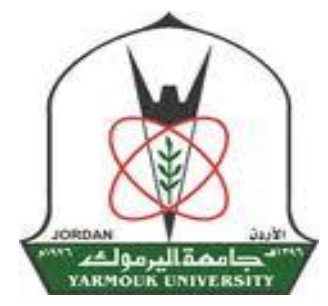

Department of English Language and Literature Yarmouk University

Irbid- Jordan

\title{
Implicit Compliments in Jordanian Arabic
}

By:

Hussein Hameed Al-Batayneh

\author{
Supervisor: \\ Prof. Mahmud Wardat \\ 2013
}




\title{
Implicit Compliments in Jordanian Arabic
}

\author{
By:
}

Hussein Hameed Al-Batayneh

B.A. English Language and Literature, Yarmouk University, Jordan

A Thesis Submitted in Partial Fulfillment of the Requirements of the Degree of Master of Arts in Linguistics in the Department of English Language and Literature

Yarmouk University, Irbid, Jordan

\section{Examining Committee:}

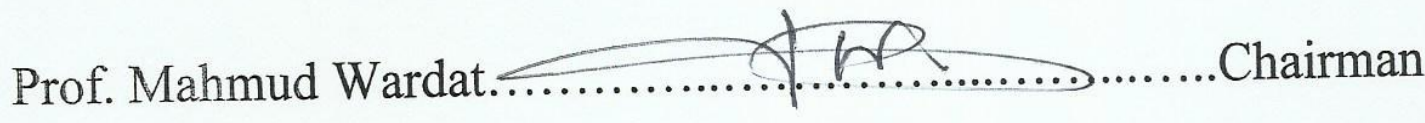

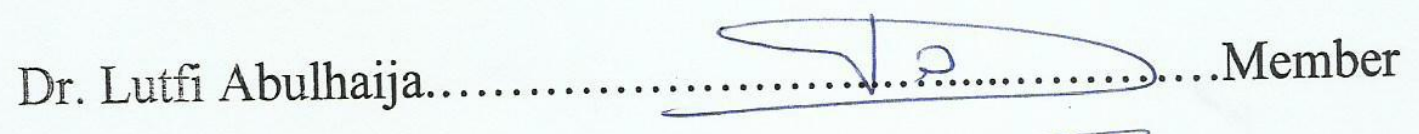
Prof. Mahmoud Al-Khatib............................... External Examiner 


\section{Acknowledgements}

First and foremost, all thanks are due to Almighty Allah Who guides us along the straight path. My warm and sincere thanks go to my supervisor Prof. Mahmud Wardat for the precious time he has spent helping me write this thesis. My deepest gratitude also goes to Dr. Lutfi Abulhaija and Prof. Mahmoud AlKhatib for their invaluable comments and suggestions which definitely improved the quality of this thesis.

A big thank-you must be extended to my close friend Saleem Abdoul Hady for his appreciated contributions. 


\section{Table of Contents}

Acknowledgements.

Table of Contents.

List of Phonetic Symbols.

List of Transcribing Conventions

List of Abbreviations

English Abstract

Chapter one: Theoretical Background

1. Introduction

1.1. What is a compliment? Towards a typology of compliments

1.2. Complimenting as a speech act

1.3. Complimenting as facework

1.4. The importance of contextuality in complimenting

1.5. Functions of compliments.

1.6. Topics of compliments

1.7. Compliment responses 
2.1. Introduction

2.2. Explicit compliments

2.2.1. Syntactic, semantic and morphological studies

2.2.2. Sociolinguistic studies.

2.2.3. Contrastive studies.

2.3. Implicit compliments.

Chapter Three: Methods and Procedures.

3.1. Introduction

3.2. Statement of the problem

3.3. Purpose of the study

3.4. Research questions

3.5. Hypotheses.

3.6. Significance of the study.......

3.7. Variables of the study.

3.8. Data collection

3.9. Data analysis 
3.10. Population and sampling

3.10.1. Population.

3.10.2. Sampling.

3.11. Limitations of the study

Chapter Four: Findings and Discussion

4.1. Introduction

4.2. Formulaic implicit compliments

4.2.1. Implicit compliments as idiomatic expressions

4.2.2. Implicit compliments as formulaic structures.

4.3. Nonformulaic implicit compliments

4.3.1. Implicit compliments involving comparisons....

4.3.1.1. Personal comparisons.

4.3.1.1.1. Specific personal comparisons.

4.3.1.1.2. Generic personal comparisons

4.3.1.2. Impersonal comparisons

4.3.2. Implicit compliments referring to achievements

Chapter Five: Summary, Conclusions and Recommendations. 
5.1. Summary

5.1.1. Findings.

5.1.2. Cases of implicit compliments

5.1.3. Revisiting the research questions.

5.2. Conclusions

5.3. Recommendations.

References.

Abstract in Arabic .$(164)$ 


\section{List of Phonetic Symbols}

\section{Consonants:}

\begin{tabular}{|c|c|c|}
\hline Symbol & Description & Arabic Consonant \\
\hline$?$ & Glottal stop & i \\
\hline $\mathrm{b}$ & Voiced bilabial stop & ب \\
\hline $\mathrm{t}$ & Voiceless dento-alveolar stop & $ت$ \\
\hline$\theta$ & Voiceless interdental fricative & $\dot{H}$ \\
\hline $\mathrm{j}$ & Voiced post-alveolar affricate & ج \\
\hline $\mathrm{H}$ & Voiceless pharyngeal fricative & $\tau$ \\
\hline $\mathrm{x}$ & Voiceless velar fricative & $\dot{\tau}$ \\
\hline $\mathrm{d}$ & Voiced dento-alveolar stop & $د$ \\
\hline ð & Voiced interdental fricative & $\dot{j}$ \\
\hline $\mathrm{r}$ & Voiced alveo-palatal trill & J \\
\hline $\mathrm{z}$ & Voiced alveolar fricative & j \\
\hline $\mathrm{s}$ & Voiceless alveolar fricative & س \\
\hline$\check{\mathrm{s}}$ & Voiceless alveo-palatal fricative & ش \\
\hline $\mathrm{S}$ & Voiceless alveolar emphatic fricative & ص \\
\hline $\mathrm{D}$ & Voiced alveolar emphatic stop & 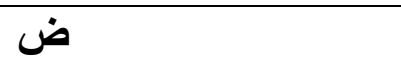 \\
\hline $\mathrm{T}$ & Voiceless dento-alveolar emphatic fricative & b \\
\hline $\mathrm{Z}$ & Voiced interdental emphatic fricative & ظ \\
\hline
\end{tabular}




\begin{tabular}{|c|c|c|}
\hline 9 & Voiced pharyngeal fricative & $\varepsilon$ \\
\hline 8 & Voiced velar fricative & $\dot{\varepsilon}$ \\
\hline $\mathrm{f}$ & Voiceless labio-dental fricative & ف \\
\hline $\mathrm{g}$ & Voiceless uvular stop & ق \\
\hline $\mathrm{k}$ & Voiceless velar stop & S \\
\hline 1 & Voiced alveolar lateral & J \\
\hline $\mathrm{m}$ & Voiced bilabial nasal & 5 \\
\hline $\mathrm{n}$ & Voiced alveolar nasal & ن \\
\hline $\mathrm{h}$ & Voiceless glottal fricative & $\Delta$ \\
\hline $\mathrm{w}$ & Voiced labiovelar glide & 9 \\
\hline $\mathrm{y}$ & Voiced palatal glide & ي \\
\hline q & Voiced velar stop & ق (العامية) \\
\hline
\end{tabular}

\section{Vowels:}

\begin{tabular}{|l|l|l|}
\hline Vowel & Description & Symbol \\
\hline fatHah & Short low vowel & a \\
\hline Dammah & Short high back vowel & u \\
\hline kasrah & Short high front vowel & i \\
\hline
\end{tabular}

Symbols are doubled for long variants of the above vowels (aa, uu, ii). 


\section{Transcribing Conventions}

This system of transcribing talk to written form is adapted from Atkinson and Heritage (1984: ix-xvi). The symbols are used to represent characteristics of talk besides the words themselves, such as pauses, overlapping talk, voice intonation, and laughter. For the sake of clarity, the words involving the speech act of implicit compliment are italicized throughout the thesis.

\begin{tabular}{|c|c|}
\hline Symbol & Meaning \\
\hline & Dots indicate talk omitted from the data segment. \\
\hline [ ] & $\begin{array}{l}\text { Square brackets between lines or bracketing two lines of } \\
\text { talk indicate the beginning and end of overlapping talk. }\end{array}$ \\
\hline$(0.4)$ & $\begin{array}{l}\text { Numbers in parentheses represent pause measured to the } \\
\text { nearest tenth of a second. }\end{array}$ \\
\hline (.) & $\begin{array}{l}\text { A dot enclosed in parentheses indicates a short, untimed } \\
\text { pause (sometimes called a micropause), generally less } \\
\text { than two- or three-tenths of a second. }\end{array}$ \\
\hline $\begin{array}{l}\text { End of line }=\text { start of } \\
\text { line }\end{array}$ & $\begin{array}{l}\text { Equal signs are latching symbols. When attached to the } \\
\text { end of one line and the beginning of another, they } \\
\text { indicate that the later talk was "latched onto" the earlier } \\
\text { talk with no hesitation, perhaps without even waiting the } \\
\text { normal conversational rhythm or "beat". }\end{array}$ \\
\hline Wait a minute & Underlining shows a vocal stress or emphasis. \\
\hline Oh: no::: & $\begin{array}{l}\text { Colons indicate an elongated syllable; the more colons, } \\
\text { the more the syllable or sound is stretched. }\end{array}$ \\
\hline Wait a minu- & A hyphen shows a sudden cutoff of speech. \\
\hline This is a (rehash) & $\begin{array}{l}\text { Parentheses around words indicate a transcriber doubt } \\
\text { about what those words are, as in the case of softly } \\
\text { spoken or overlapped talk. }\end{array}$ \\
\hline This is a ( ) & $\begin{array}{l}\text { Empty parentheses indicate that some talk was not } \\
\text { audible or interpretable at all. }\end{array}$ \\
\hline$(($ coughing $))$ & Double parentheses enclose a transcriber's comments. \\
\hline $\begin{array}{l}\text { When? thats all } \\
\text { right. Well, I don't } \\
\text { know, }\end{array}$ & $\begin{array}{l}\text { Punctuation marks are generally used to indicate a pitch } \\
\text { level rather than a sentence type. The apostrophe' } \\
\text { indicates missing speech sounds and normal } \\
\text { contractions. The period indicates a drop in pitch; the } \\
\text { question mark shows a rising pitch (not necessarily a }\end{array}$ \\
\hline
\end{tabular}




\begin{tabular}{|l|l|}
\hline & $\begin{array}{l}\text { question), and the comma represents a flat pitch or a } \\
\text { slight rising-then-falling pitch. When used, the } \\
\text { exclamation mark (!) shows lively or animated speech. }\end{array}$ \\
\hline .hh & $\begin{array}{l}\text { The h preceded by a period represents an audible } \\
\text { inbreath. Longer sounds are transcribed using a longer } \\
\text { string: hhhh }\end{array}$ \\
\hline $\begin{array}{l}\text { hh } \\
\text { st(h) upid }\end{array}$ & $\begin{array}{l}\text { The h without a leading period represents audible } \\
\text { exhaling, sometimes associated with laughter, and } \\
\text { laughter itself is transcribed using "heh" or "hah" or } \\
\text { something similar. When laugh tokens are embedded in } \\
\text { a word, they are often represented by an h in } \\
\text { parentheses. }\end{array}$ \\
\hline pt & $\begin{array}{l}\text { The letters pt by themselves represent a lip smack, which } \\
\text { occasionally occurs just as a speaker begins to talk. }\end{array}$ \\
\hline $\begin{array}{l}\text { Did juh ever hear } \\
\text { uv'im }\end{array}$ & $\begin{array}{l}\text { Modified spelling is used to suggest something of the } \\
\text { pronunciation. }\end{array}$ \\
\hline $\begin{array}{l}\text { 9. A: } \\
\text { 10. B: }\end{array}$ & $\begin{array}{l}\text { For ease of identification in the discussion, speakers are } \\
\text { identified by letters, and each line is numbered. }\end{array}$ \\
\hline
\end{tabular}




\section{List of Abbreviations}

\begin{tabular}{|l|l|}
\hline ADJ & adjective \\
\hline ADV & adverb \\
\hline INT & intensifier \\
\hline NP & noun phrase \\
\hline PP & prepositional phrase \\
\hline PRO & pronoun \\
\hline V & verb \\
\hline
\end{tabular}




\section{English Abstract}

This thesis is a sociopragmatic study of the speech act of implicit complimenting among Jordanian people. The researcher follows the ethnomethodological approach in order to identify the construction and organization of such a speech act. Such an approach renders the speech act of implicit compliment as an undivided, integral part of the discourse in which it occurs. Adopting this orientation enables the researcher to focus on the motives behind choosing an implicit compliment instead of an explicit one at a specific time of the discourse. The results of the study show that implicit compliments are different from explicit ones and that such a speech act belongs to a different category. The study also shows that implicit compliments convey many interactional functions that serve the speaker and the addressee and that some functions serve them both. Concerning the responses to implicit compliments, the study shows that implicit compliments have responses different from explicit ones. The study concludes with the claim that implicit compliments are similar to other speech acts and should be studied away from the theory of face to reach different findings related to the context of the speech event.

Key Words: Implicitness, explicitness, speech act, discourse analysis, inferences, pragmatics, sociolinguistics 


\section{Chapter one}

\section{Theoretical Background}

\section{Introduction}

This thesis is a sociopragmatic study of the speech act of implicit complimenting among Jordanian people. Complimenting behavior has become an intriguing topic in linguistics (Boyle 2000:26) and its sub-branches since it happens with a high frequency in our daily life (We all give and receive compliments to a lesser or greater extent) and since it greatly affects our relationships with other people. However, although this speech act has been widely investigated (e.g., Billmyer, 1990; Chung-hye, 1992; Kryston-Morales, 1997; Lorenzo-Dus, 2001), the focus of previous papers and dissertations has paid lesser attention to compliments conducted implicitly (see Ch.2). Therefore, this study is an attempt to redress the balance in favor of implicit compliments. To reach a satisfying understanding of this speech act, the researcher follows the ethnomethodological approach in his analysis of the discourse of compliments; an approach to sociological inquiry by which researchers "seek to discover the interpretive practices through which interactants produce, recognize, and interpret their own and others' actions" (Pomerantz 1988:361). 
Adopting such an approach, the researcher is hopefully able to provide a detailed, naturalistic account of compliment practice within specific domains of socially organized actions. Lakoff (2003), though referring to apologies, emphasizes the importance of the discourse analysis of speech acts as follows:

We have to understand apologies as contributions to a large discourse, viewing them from a variety of perspectives, formal and functional, cognitive and interactive, individual and group, intralanguage and societal; to examine the apology from the perspective of phonology, syntax, lexical semantics, speech act pragmatics, conversational analysis, narratology, and sociolinguistics. In some ways, any speech act verb might illustrate the point. (Lakoff 2003:201)

In a similar vein, Van Dijk (1998:383) argues that pragmatics should deal with speech acts within the field of discourse, and restricting the study to isolated sentences is inappropriate since "speech acts usually do not come alone, but appear as functional elements in locally and globally coherent sequences". Such a view explains that the appropriateness of speech acts depends on their position in sequences of utterances. However, the researcher, depending on the previous considerations, highlights the fact that applying discourse analysis plays a crucial role in unfolding the social and linguistic functions of complimenting in the Jordanian speech community. Apart from functions related to enhancing politeness and saving face, interactants achieve many interactional purposes 
which they cannot reach unless they opt for implicit instead of explicit compliments.

\subsection{What is a compliment? Towards a categorization of compliments}

In this section, relevant definitions of compliments are provided in order to clarify the concept under concern; there are multi- perspectives through which this speech act is studied. Generally speaking, there are three types of compliment behaviour: explicit, implicit and indirect. Before the researcher explains them, it is appropriate to list some definitions related to different approaches.

Wierzbicka (1987) deals with the notion of speech act theory from the second language acquisition perspective, suggesting the following definition:

I perceive something good about your Y.

I want to say something good about you because of that.

I say: (something good about X and X's Y)

I feel something good about thinking about it.

I say this because I want to cause you to know that I am thinking something good about you.

I assume that you will feel something good because of that.

(Wierzbicka 1987:201)

From this perspective, she tries to show the differences between complimenting and other related verbs such as praise, approve and boast. For example, 
although complimenting and praising both require positive judgements, complimenting has to apply to the addressee: "One can praise, but not compliment, someone who is absent" (ibid.). Nonetheless, she treats complimenting from only one side; her definition may be applicable for explicit compliments but not for other types.

From the applied linguistics perspective, Wolfson (1983:89) defines compliments as "social lubricants" whose main function is "to create or to maintain solidarity between interlocutors." Such a definition does not accurately describe the idea being defined; it explains what a compliment does in interaction (only one of the functions) instead of focusing on the essential features of the term.

From a pragmatic point of view, Holmes (1988:446) offers a much more analytic and informative definition, compared to previous attempts. Holmes provides the following definition:
A compliment is a speech act which explicitly or implicitly attributes credit to someone other than the speaker, usually the person addressed, for some 'good' (possession, characteristic, skill, etc.) which is positively valued by the speaker and the hearer.

As stated above, this definition is more holistic since it deals with the issue from two sides, namely, explicit and implicit forms of complimenting. In addition to 
mentioning the essential features associated with the term, Holmes draws the attention to the fact that compliments may happen in an implied manner; she states that even when a compliment appears to a third person, it may be indirectly complimenting the addressee. She provides this example:
R's old school friend is visiting and comments on one of the children's manners.
C (complimenter): What a polite child!
R (recipient): Thank you. We do our best.

Since the utterance indirectly attributes credit to the addressee for good manners, it can be interpreted as paying a compliment to the addressee (Holmes, 1988:485). This discussion leads us to our first note of the classification of compliments. It is obvious that we have till now referred to two kinds of compliments: explicit and implicit.

Considering the difference between them, we can notice that, according to Boyle (2000:18), compliments can be considered explicit when they "are recognized as compliments outside of context, being realized by a small set of conventional formulae." Leaving aside other context-bound issues such as irony or sarcasm, any ordinary speaker would, in fact, recognize the following expressions as compliments because of their linguistic realization: 'I love your shirt' or 'What a lovely dress you're wearing today!' Explicit compliments are, thus, linguistically realized by declarative sentences which, in turn, can be affirmative or exclamative. There is also a limited lexical choice of verbs (e.g., 
love, like) and adjectives (e.g., beautiful, nice, lovely), as the extensive research on the topic has shown (see Chapter 2.1).

Implicit compliments are those "in which the value judgement is presupposed and/or implicated by Gricean maxims" (Boyle 2000:28). In other words, they do not necessarily have a "fixed" linguistic form like explicit compliments do, and hearers need to infer the corresponding implicature for their interpretation. Boyle (2000:28) gives the following examples to illustrate implicit compliments in English: "I wish I could manage my work like you do" and "Your husband is a very lucky man."

However, in addition to the types of compliments stated above, there is another type which is a reported compliment. Yuan (2001: 286) points out that compliments can also be indirect. The speaker does not make the compliment himself or herself but quotes somebody else as saying something complimentary about the addressee. Yuan exemplifies this type in the following example:

Sun Ping said that the preserved vegetables you made were the most delicious!

In this case, Sun Ping, the original complimenter, was present when the researcher reported her compliment to the recipient of the compliment. Intuitively it seems that such embedded or reported compliments may be fairly 
frequent, but they do not seem to have been treated systematically in the relevant research literature.

To sum up, in this section relevant definitions of the speech act of complimenting are provided from different perspectives, namely, second language acquisition (Wierzbicka, 1987), applied linguistics (Wolfson,1983), and pragmatics (Holmes,1988). And it is claimed that Holmes' (1988:446) definition is the most appropriate one since it provides the linguistic and social features of the term; therefore, the discussion of the forthcoming examples will be based on it. Moreover, three types of compliments are explained, namely, explicit, implicit and embedded or reported compliments. To the best knowledge of the researcher, the third type is not mentioned in the literature except that of Yuan (2001).

\subsection{Complimenting as a speech act}

In his well-known book How to Do Things with Words, Austin (1962) explains that 'sense' (the literal meanings of utterances) is not the main function of language since when we speak, we do actions with our utterances. Austin distinguishes three aspects of meanings in language use: 1) the locution, 2) the illocution and 3) the perlocution. The locution can be understood at the semantic level: the literal meaning of the words uttered. Austin (1962:94) explains it as follows: 
[Locution] includes the utterance of certain noises, the utterance of certain words in a certain construction, and the utterance of them with a certain 'meaning' [...] with a certain sense and with a certain reference.

Therefore, we can say that locution is when 'to say something is to do something' (Austin 1962:108). All constative utterances are locutionary by default as 'to say something is to say something'. Illocution is when 'in saying something an act is performed' (Austin1962:99), such as one is 'ordering someone', and perlocution is when 'by saying something an act is performed (1962:108), as in "by saying $x$ I was $y$-ing him”: 'by saying stop' I was warning him.' In other words, the illocution is the force of an utterance to perform actions (the utterance of a statement like 'I promise to do so-and-so' is best understood as doing something — making a promise), and this usually produces some effects on the hearer (the perlocution).

Austin (1962:5) proposes that there are only two types of utterances: performative and constative; the first type can be understood as utterances:

[...] do not 'describe' or 'report' or constate anything at all, are not 'true or false'; and [...] the uttering of the sentence is, or is part of, the doing of an action, which again would not normally be described as saying something.

There are also 'constative utterances'; uttering a constative is 'saying something' that has the property of being either true or false (Austin 2000:351). 
So the constative includes all descriptive utterances, statements of fact, definitions, and so forth.

A performative utterance can be viewed as a 'speech act' where "the uttering of the words is $[\ldots]$ the leading incident in the performance of an act, [...] the performance of which is also the object of the utterance" (Austin 1962:8). Some examples of this type of utterances include:

a. 'I take this woman to be my lawful wedded wife.'

b. 'I name this ship the Queen Elizabeth.'

c. 'I give and bequeath my watch to my brother.'

d. 'I bet you sixpence it will rain tomorrow.' (Austin 1962:5)

Austin's other contribution was the notion of 'felicity conditions' that make performative utterances possible. He proposes that there are certain rules available to interlocutors to make sense of the speech acts. For instance, sincerity conditions, one of the components of felicity conditions, require speakers to perform speech acts in a sincere manner: these performative verbs are only effective if speakers mean what they say. However, as one can readily find counterexamples, speech acts need not be realized with performative verbs or performed with sincere intentions. In the case of complimenting, it is common to find compliments in forms such as 'Your hair is really nice' or 'Where did you cut your hair?' without any performative verbs. 
Searle (1969:58), one of many students of Austin's studying at Oxford at the time, attempts to solve this problem by introducing the notion of 'indirect speech acts'. Indirect speech acts can be explained as some linguistic activity manifested through the use of non-prototypical forms. The utterance 'Where did you cut your hair?' can be interpreted as a compliment although it does not have the verb 'compliment.' These indirect patterns are frequently observed and the data consists only of this type of compliments where the interpretation of the utterance depends heavily on the context rather than on the literal meaning of the words used.

\subsection{Complimenting as facework}

Brown and Levinson (1987) are among the most influential scholars in the history of linguistic politeness theory. They introduce to linguistics the notion of 'face', trying to explain linguistic politeness phenomena. They (1987:61) define face as "something that is emotionally invested, and that can be lost, maintained, or enhanced, and must be constantly attended to in interaction." They further distinguish two types of face: negative and positive face as follows:

(a) Negative face: the basic claim to territories, personal preserves, rights to non-distraction - i.e. to freedom of action and freedom from imposition. 
(b) Positive face: the positive consistent self-image or 'personality' (crucially including the desire that this selfimage be appreciated and approved of) claimed by interactants. (Brown and Levinson 1987:61)

Because face is "the public self-image" that is open to negotiation through interaction with others, face can be threatened and damaged as well as enhanced and motivated. Brown and Levinson refer to some speech situations where the interlocutors can possibly lose their face, and they consider speech acts used in such situations as Face- Threatening Acts (FTAs).

Another point in Brown and Levinson's (1987:63) theory that should be noted here is that they consider politeness 'strategy.' They propose positive and negative politeness strategies that both address positive and negative face wants independently. The positive politeness strategy includes noticing and attending to the hearer's face, seeking agreement, avoiding disagreement, and joking. These tend to be used as in-group identity markers. On the other hand, the negative politeness strategy includes being indirect conventionally, hedging, giving deference, apologizing, and so forth. Consequently, Brown and Levinson consider the speech act of complimenting to be one of the most obvious positive politeness strategies since complimenters attend to the complimentees' wants and needs.

However, the previous view has been widely criticized. Meyerhoff (1999:229) argues that "it becomes extremely unlikely that a specific routine or 
gesture will ever be interpretable purely as a gesture of positive or negative politeness." In some cultures, such as the Samoan culture (Holmes and Brown 1987:526), when one compliments on something which belongs to an addressee, this puts the complimented under pressure to offer the object to the addressee as a gift. Therefore, we cannot consider this speech act or another one to be a positive/negative politeness strategy without referring to the context in which the speech act occurs. In other words, complimenting as a speech act is culturebound and context-bound.

\subsection{The importance of contextuality in complimenting}

In the previous section, it is claimed that complimenting cannot be taken for granted as a positive politeness strategy without considering the context. This idea has been reinforced by Mills (2003) who highlights the importance of taking the context into consideration when dealing with any speech act. He (2003:219) states that "compliments can also function in very different ways depending on the context." Furthermore, Holmes (1995:119) indicates the possibility of compliments functioning as potential FTAs: "compliments may have a darker side then. For some recipients, in some contexts, an apparent compliment may be experienced negatively, or as face-threatening. They may be patronizing or offensively flattering. They may also, of course, be sarcastic".

Eckert and McConnell-Ginet (2003:146) suggest that "inappropriate compliments are moves that might do wanted facework for the addressee in 
some situation, but do not do the facework called for in the utterance context." Eckert and McConnell-Ginet's point draws our attention to the fact that the complimentees' role of decoding the illocutionary force of a compliment is as important as the complimenters' role of encoding the compliment. In other words, in each speech situation, analysts need to analyze compliments from two different perspectives, the intended meaning of the speaker and the interpreted meaning of the addressee. This view appears crystal clear in both explicit and implicit compliments, but for implicit compliments, it is more indicative since the positive meanings of the compliment are not inherent in the words themselves; complimentees depend on their inferences in order to understand the intended meaning of the utterance (what is implicated by speakers in conversations).

This discussion leads us to refer to Grice $(1969,1975)$ who introduces the notion of conventional and conversational implicature. Unlike conventional implicature, which is expressed as part of the literal meanings of words, conversational implicature can be inferred based on speakers' and addressees' shared knowledge about the world and the accepted ways of behaving in conversations (cultural- and context-dependent interaction). Since conversational implicature is not just generated by the inherent or literal meanings of the words uttered, decoding conversational implicature heavily relies on the context that the interactants are involved in. 
The addressees' ability to construct inferences cannot be successfully accomplished without depending on the "contextualization clues." Gumperz (1999:461) introduces the notion "contextualization cue" and defines it as follows:
Any verbal sign which when processed in co-occurrence with symbolic grammatical and lexical signs serves to construct the contextual ground for situated interpretations, and thereby affects how constituent messages are understood.

Some examples of these cues are prosody, paralinguistic signs, code choice, choice of lexical forms or formulaic expressions, and verb tense and aspect (Gumperz 1992: 230-235). However, in Gumperz's point of view, interactants follow certain verbal signs to build appropriate inferences which help them avoid conversation breakdown. Contextualization clues, then, enable speakers to correctly understand and interpret each other's utterances. Being so, the conversation goes smoothly with as minimum interruptions as possible.

\subsection{Functions of compliments}

As explained above, Mills (2003) highlights the importance of taking the context into consideration when dealing with any speech act. He states that "compliments can also function in very different ways depending on the context" (219). Unfortunately, the study of compliments has focused on what 
compliments do in society instead of focusing on what they do in interaction. This narrow view is caused by the way researchers collect their data; Holmes (1988:507) notices that almost all studies adopt ethnographic method for data collection. The study of this speech act has been limited to the explicit form of compliments; consequently, the functions are limited as well.

The general, out-of-context functions of compliments have been explained as follows: Wolfson (1983:89) mentions that compliments are social lubricants that create or maintain rapport. By performing this speech event, people can not only maintain mutual harmony but also re-establish reciprocal social relationship. Furthermore, complimenting is also used to alleviate the weightiness of employing a face threatening act (FTA) in the discourse (Holmes 1986; Brown and Levinson 1987). Holmes (1988: 464) suggests that compliments serve as "solidarity signals, commenting on friendships, attenuating demands, smoothing ruffled feathers and bridging gaps created by possible offenses." In general, the previous functions of compliments can be summarized as follows: to make people feel good. The legitimate question here is: What do these studies add to our knowledge? Doesn't any layman know the merits of compliments as stated above?

However, Eckert and McConnell-Ginet's (2003, cited in Adachi 2011: 22-24) discussion of the potential intentions of complimenters suggests an attempt to add different functions to this speech event; they distinguish three 
types of compliments: 1) routine/formulaic compliments, 2) sarcastic compliments and 3) deceptive compliments. First, the intention of speakers in routine/formulaic compliments is to simply give compliments and not to evaluate. The function of this type is to show good manners and to maintain social class hierarchies. Speakers are expected to say such pretty words as etiquette in specific contexts like the dinner table.

For the second type, 'sarcastic compliments,' Eckert and McConnellGinet (2003:154) state that "the sarcastic compliment does something like mime an apparent compliment in order to mock it. It insults by appearing to compliment by making obvious that the putative positive evaluation in this situation is judged laughable, absurdly off the mark". Therefore, the complimenter's intention is to convey a caustic remark in order to insult or scorn the addressee. Finally, deceptive compliments are produced, in general, from self-interest. Persons who pay this type of compliment might be regarded as "flatterers" or even as "phonies". In order to differentiate between the first and the third type, Eckert and McConnell-Ginet (2003:155) suggest that although the function of deceptive complimenting is to make the addressee feel good about himself/herself, it is "not an end, but simply a means." To illustrate, staff at clothes shops compliment customers only to make sales out of the interaction. 
However, the typology above may be questioned in two folds; firstly, we can argue that these different types of compliments are interwoven and overlapped to the extent that we cannot in all cases differentiate between them, especially between routine and deceptive compliments. Secondly, the complimentees cannot be sure about the complimenters' intentions. The speaker's intention may be misinterpreted in some interactions. To illustrate, Holmes (1995:119) indicates that "an apparent compliment may be experienced negatively or as face-threatening."

In this section, it is explained that the study of compliments has focused on what compliments do in society instead of focusing on what they do in interaction. Further, it is claimed that the ethnographic method used for data collection restricts the researchers' analyses. Therefore, studying the illocutionary force of complimenting, especially implicit compliments, at the discourse level may provide the researcher with some plausible findings about the complimenters' motives (their internal needs) to opt for an implicit compliment rather than an explicit one.

\subsection{Topics of compliments}

Apart from deceptive compliments, complimenting is a speech act that refers to something which is positively valued by both the participants and attributed to the addressee. This seems to permit a variety of possible topics for compliments. Herbert (1997: 497) proposes that "Compliment events provide 
interesting information on sociocultural values and organization" and "the topics of compliments reveal the values which are positively regarded within some particular society."

Therefore, objects of compliments directly reflect not only what individuals value, but also what the whole society values. As Manes (1983:96) puts it, a compliment is "a mirror of cultural values." She (1983:97) suggests that "compliments are of particular interest, however, in regard to the reflection and expression of cultural values because of their nature as judgements, overt expressions of approval or admiration of another's work, appearance, or taste." Topic selection within compliments can represent cultural differences as every community has its own societal values. Wieland (1995:811) suggests what is considered to be acceptable as the object of a compliment is cultural-bound. In her study on compliments exchanged between Americans and French at dinner table in France, the Americans preferred to compliment on appearance more than the French.

Araki and Barnlund (1985), in a comparative study of compliments between American English and Japanese, show that the Japanese tended to compliment on personal traits more significantly than Americans while Americans' focus was on the addressee's appearance and personal traits. Adachi (2007) also found that the British students focused on more extrinsic features about addressees - appearance and possessions - whereas the Japanese 
students were more likely to compliment on intrinsic features such as personality and ability.

In general, the main topics for compliments are appearance, clothing, emotions, helping and service, performance, personality traits and possessions. Understanding what is appropriate to compliment on in a specific context and/or culture is an important factor to be taken into consideration (Eckert and McConnell-Ginet 2003; Manes 1983; Wieland 1995) since complimenting on an inappropriate topic can be face-threatening to addressees. To sum up, we can say that there are different topics which would only be appropriate in specific speech situations regarding the different values based on the community's ideology

\subsection{Compliment responses}

With regard to compliment responses, it was once strongly believed that accepting a compliment is the most appropriate way of responding to compliments. In Herbert's (1990:207 cited in Adachi 2011: 218) words, "there is virtual unanimity among speakers of English that the prescriptively 'correct' response to a compliment is thank you." Herbert also cites a motivating quote from an American etiquette book:

When you are complimented, the only response necessary is “Thank you." Don't disparage yourself. If someone admires your dress, don't say, “This old thing, I got it at a bargain 
sale." A simple thank you is sufficient. (Johnson 1979:4344, cited in Herbert 1986:76)

However, the situation is not that simple. Pomerantz (1978) investigates compliment responses from a conversation analytic point of view and finds that the recipients of compliments face two conflicting constraints, or in other words, an interactional dilemma:

A) Agree with and/or accept compliments

B) Avoid self-praise Pomerantz (1978:81-82 cited in Chen 2010: 80)

The first constraint (A) can be illustrated as follows: interactants generally prefer to avoid any conflict in conversation; being so, complimentees accept compliments, often expressed by appreciation tokens such as 'thank you.' On the other hand, because compliments are, in fact, positive assessments, agreeing with compliments implies self-praise, which is what the second constraint (B) inclines speakers to avoid; therefore, they downgrade the value of the object of the compliment (e.g., 'That's a nice blouse!' 'It keeps out the cold'). Constraint B, thus, encourages complimentees to reject compliments.

Next, building on Pomerantz (1978), Herbert (1990) discusses twelve compliment response types found in American English. His framework also starts with the two conflicting systems of agreement and disagreement, on the one hand, and acceptance and non-acceptance, on the other. His study is based 
on 1,062 compliments collected by his university students from State University of New York between 1980 and 1983. The twelve response types are reviewed as follows:

Response types

Agreement

$$
\begin{aligned}
& \text { Acceptance 1. Appreciation token } \\
& \text { "Thanks" } \\
& \text { 2. Comment acceptance } \\
& \text { "Yeah, it's my favorite too." } \\
& \text { 3. Praise upgrade } \\
& \text { "Really brings out the blue in } \\
& \text { my eyes, doesn't it?" }
\end{aligned}
$$

Nonacceptance

\section{Comment history}

"I bought it for the trip to

Arizona"

5. Reassignment

"My brother gave it to me"

6. Return

"So's yours"

$\underline{\text { Disagreement }}$

7. Scale down

"It's really quite old"

\section{Question}

"Do you really think so?"

\section{Disagreement}

"I hate it."

\section{Qualification}

"It's alright, but Len's is nicer"

\section{No acknowledgement \\ [silence]}

Other

Interpretations

\section{Request interpretation}

"You wanna borrow this one too?"

(Herbert 1990:208-211)

In her studies of compliment responses in New Zealand English, Holmes (1995) adopts a different framework from the model mentioned above. She adds 
another category named "deflect/evade" besides "acceptance" and "rejection" as first introduced by Pomerantz. Holmes' framework of compliment responses is shown below.

Response type
A. Accept
1. Appreciation/agreement token "Thanks, yes"

2. Agreeing utterance "I think it's lovely too"

3. Downgrading utterance "It's not too bad, is it"

4. Return compliment "You're looking good too"

B. Reject

1. Disagreeing utterance "I'm afraid I don't like it much"

2. Question accuracy "Is beautiful the right word?"

3. Challenging sincerity "You don't really mean that"

C. Deflect/Evade 1. Shift credit "My mother knitted it"

2. Informative comment "I bought it at that Vibrant Knits place"

3. Ignore "It's time we were leaving, isn't it?"

4. Legitimate evasion Context needed to illustrate

5. Request reassurance "Do you really think so?"

(Holmes 1995:141)

In the data collected in this thesis, deflecting or evading compliments is not found to be an important interactional strategy in responding to compliments; therefore, the current study takes Herbert's (1990) classification of compliment responses as the basic framework. 


\section{Chapter Two}

\section{Review of Related Literature}

\subsection{Introduction}

In the previous chapter, the researcher has briefly discussed some related studies in order to explain the framework within which this current study is carried out; he has touched on some key concepts and terminology provided by some influential scholars and researchers. However, for reasons of space, the aforementioned issues, although highly relevant to this chapter, are not revisited.

\subsection{Explicit compliments}

The speech act of complimenting is extensively studied in the literature as it appears in this section. Golato (2002, cited in Golato, 2003) notices that compliments and compliment responses have been studied in detail in eleven different languages and in six varieties of English alone, and they have been studied from a variety of different perspectives as well. However, the previous observation is correct only if we regard one type of this speech act, namely, explicit compliments. To the best of researcher's knowledge, only three articles have been directed to the other rarer speech act, namely, implicit compliments (see 2.2. Implicit compliments). Nonetheless, in this section the researcher 
presents some of the studies related to explicit compliments with reference to the different fields of linguistics within which these studies are conducted.

\subsubsection{Syntactic, semantic and morphological studies}

Explicit compliments have been extensively studied and confirmed the findings of Manes and Wolfson (1981). Based on American English daily conversation data, their results show that explicit compliments follow specific syntactic patterns. The following patterns are indicative of the formulaic nature of explicit compliments:

(1) NP \{is, looks $\}$ (really) ADJ (PP)

e.g. Your cell phone is very fashionable.

(2) I (really) \{like, love $\}$ NP

e.g. I love your new pairs of glasses

(3) PRO is (really) (a) (ADJ) NP

e.g. You are really a good teacher.

(4) You V (a) (really) ADJ NP

e.g. You did a good job.

(5) You V (NP) (really) ADV (PP)

e.g. You cook really deliciously.

(6) You have (a) (really) ADJ NP

e.g. You have such an attractive figure!

(7) What (a) (ADJ) NP!

e.g. What a great job you did!

(8) ADJ (NP)! 
e.g. Good job!

(9) Isn't NP ADJ!

e.g. Isn’t your courage praiseworthy! (Manes \&Wolfson 1981:177)

Manes and Wolfson (1981) state that $85 \%$ of the data set was accounted for by only three patterns of (1) - (3). This is consistent in Holmes' (1995) study on New Zealand compliments. The following table shows the distribution of syntactic patterns as follows:

1. NP BE (LOOKING) (INT) ADJ

e.g. That coat is really great

2. I (INT) LIKE NP

e.g. I simply love that skirt.

3. PRO BE (a) (INT) ADJ NP

e.g. That's a very nice coat.

4. What (a) (ADJ) NP!

e.g. What lovely children!

5. (INT) ADJ (NP)

e.g. Really cool ear-rings.

6. ISNt NP ADJ!

e.g. Isn't this food wonderful! (Holmes 1995:128)

In general, the previous findings have been verified, to a greater or lesser degree, by other linguists (cf. Wolfson 1981, 1983, 1984; Creese 1991; YlänneMcEwen 1993). 
From a semantic perspective, Manes and Wolfson (1981 cited in Adachi 2011: 35) find that positive adjectives accounted for $80 \%$ of their collected data. According to Manes and Wolfson (1981), two thirds of their data accounted for the following five adjectives: nice, good, pretty, beautiful and great. In total, as much as $96 \%$ of all compliments found in Manes and Wolfson's American English corpus are expressed with either the semantically positive adjectives mentioned above and/or the verbs like and love. However, the previous findings indicate that there are a limited number of lexical items, that is, positively evaluative words, to be used in complimenting. Such a suggestion has been proven to be true in many studies on explicit compliments (cf. Wolfson 1981; Holmes 1995; Creese 1991; Daikuhara 1986; Holmes 1988, 1995; Nelson et. al. 1996; Qanbar 2012).

Explicit compliments are not only syntactically and semantically restricted, but they are also restricted morphologically. Manes and Wolfson (1981 cited in Adachi 2011: 33) suggest that there are some morphological constraints on the structure of compliments; compliments are rarely produced with comparatives or superlatives of adjectives. As for tense, they emphasize that they find no example of future tense compliments in their data. The occasional cases of progressive, present perfect and conditional can be exemplified as follows:

Comparatives: "Your accent is charming. Much nicer than ours." 
Superlatives: "Hank, that's some of the best banjo picking I've ever heard."

Progressive: "Jane, you're looking great as usual."

Present perfect: "I've always loved that shirt."

Conditionals: "I think you'd be good in law school." (Manes and Wolfson 1981:122)

To conclude, there are specific syntactic, semantic and morphological constraints imposed on the use of explicit compliments. Therefore, it is widely believed that "the speech act of complimenting is, in fact, characterized by the formulaic nature of its syntactic and semantic composition" (Manes and Wolfson 1981:123).

\subsubsection{Sociolinguistic studies}

Since sociolinguistics is the study of the relationship between language and society, especially the social variability of language, it describes why people speak differently along with the differences in gender, power, age, ethnicity, and so on. However, the study of language and gender is one of the major areas in sociolinguistics. Explicit compliment has been discussed from the perspective of gender differences, such as "Paying compliments: A sexpreferential politeness strategy" by Janet Holmes (1988). Holmes finds that females respond to compliments more than males who tend to ignore or evade a compliment. There are subtle differences between both genders regarding the strategies used for compliment responses. 
Moreover, complimenting is considered in some cases as a positive politeness strategy which attends to the addressees' positive face. Holmes (1995:124) claims that since men consider complimenting as more facethreatening, they use the speech act of compliments to achieve referential oriented goals, while women consider it as more of positive politeness strategy i.e., as a marker of solidarity. Holmes (ibid) gives one example of a male compliment that is referential goal oriented:

Mick and Brent are neighbors. They met at Brent's gate as he arrives home.

Mick: New car?

Brent: Yeah.

Mick: Looks as if it will move.

Brent: Yeah it goes well I must say. (ibid)

Moreover, Holmes (1995) finds that women prefer the rhetorical pattern (What (a) ADJ NP! - e.g. What lovely children!) while men use the minimal pattern ((INT) ADJ (NP) - e.g. Really cool ear-rings.) more than women. She attributes the reason behind this finding to the fact that women attend to the hearers' positive face considering the force of the compliment more than men who decrease the force by keeping it minimal as they are more likely to see complimenting as FTAs. Herbert (1990) supports Holmes' argument because he finds gender differences in personal focus in compliments: women use more linguistic personal pronouns than men. He observes that $82.4 \%$ of the 1062 
compliments issued by females had a "personal focus" (the 1 st and $2^{\text {nd }}$ person pronouns in compliments were used more often than the 3rd person or impersonal nouns, e.g., it/they). On the other hand, between males, this pattern was used only $31.6 \%$ of the time.

Regarding gender differences in the choice of compliment topic, Holmes (1995) found that $61 \%$ of compliments between women referred to appearance whereas between men only $36 \%$ of compliments were on appearance. Compliments on possessions were more preferable between men, but not from men to women. Concerning power play, Holmes (1995:135) mentions that although the majority of compliments occur between status-equals, when compliments occur between status-unequals, "higher status females were twice as likely to receive compliments as higher status men." She explains this by making the reference to the inequality of social status for men and women: "perhaps higher status women are perceived as more receptive to compliments (especially from men) than their male counterparts, because in the society as a whole women are generally regarded as socially subordinate, and less powerful and influential than men" (1995:136).

However, studies on explicit compliment focus not only on gender differences in the use of this speech act but also on other variables, such as power. The power variable has gained a lot of attention in the literature since it plays a significant role in giving and receiving compliments. A number of 
studies show that compliments tend to occur between status equals to enhance and reinforce the solidarity between them (Herbert 1990; Holmes 1988, 1995; Knapp et al. 1984; Wolfson 1983).

It is argued that social status places considerable constrains on the production of compliments. For example, Knapp et al. (1984) report that $71 \%$ of compliments occur between status-equals, $22 \%$ from higher to lower status and only $7 \%$ from lower to higher status. However, other social factors, such as distance, can sometimes affect social status; Matsuura (2004 cited in Adachi 2010: 41) found that American students do not compliment their professors while Japanese students compliment them as long as psychological closeness overweighs the status issue.

\subsubsection{Contrastive studies}

In this section a number of contrastive studies have been presented in order to show some of the differences between cultures regarding explicit complimentary language. Nelson et al. (1996), for instance, studying 60 compliments from Egyptians and Americans, finds that both Egyptian and American compliment patterns are adjectival, but Egyptians embed their compliments with more comparatives with references to marriage and metaphors. Yet Americans have higher frequency of complimenting more than Egyptians. Another difference concerning the topic of compliment, Egyptians compliment more on personality traits, whereas Americans tend to compliment 
more on skills and work, and both Egyptians and Americans prefer direct rather than indirect means of complimenting.

Comparing American and Japanese compliments, Barnlund and Araki (1985) reveal that Americans give compliments more often than Japanese, more frequent topics among Americans are appearance and personal traits while Japanese focus on other topics such as acts, work and study. Compared to Japanese, Americans use a wider range of adjectives. Concerning the compliments responses, Americans tend to accept, justify or extend compliments while Japanese suspect intentions, reject them, or respond by smiling or saying nothing at all (evasion).

Hernández-Herrero (1999), analyzing the complimenting behavior in Costa Rican Spanish and American English, states that while Americans utilize a limited number of lexical items and syntactic structures, Costa Rican Spanish speakers use more varied items and syntactic patterns. Another study comparing American compliments with another culture is that of Golato (2002). He compares German and American compliment responses among families and friends. The data show that while rejection, agreement and disagreement as responses to compliments are shared between the two cultures, the two languages differ in one aspect, viz. agreement sequences. However, comparing the compliment response behavior of native Chinese and Native American English speakers, Yu (2003) suggests that, while politeness is the base of 
compliments in both cultures, the different politeness strategies they use in performing their compliments indicate the crucial role that culture plays in its speakers' communications.

Placencia and Yépez (1999), studying compliments in Ecuadorian Spanish, indicate significant similarities and differences between American English and Ecuadorian Spanish regarding the topic, form and function of compliments. Concerning the topic, as in American English, compliments on appearance, for example, are the most common in Ecuadorian Spanish. There are differences, however, on what aspects of appearance are complimented on in each society: a focus on natural beauty is found to be more common in Ecuadorian Spanish than in American English. Moreover, concerning compliments on a person's life, American speakers appraise aspects related to a person's effort, and Ecuadorians allow for appraisal of natural traits. Therefore, a focus on natural personal talents is shared in both cultures.

With respect to form, i.e., the use of semantic and syntactic formulas, it is found that the use of certain lexical items and grammatical structures appeared to be of common occurrence. A difference found, however, has to do with the range of flexibility encountered in each language: In Ecuadorian Spanish, in contrast to American English, a wider range of forms and structures is available to participants for compliment exchanges. Moreover, the first person focus in American English compliments is opposed to the second person focus in 
Ecuadorian Spanish. This difference may be related to the focus found in Ecuadorian Spanish on what Americans would regard as more personal aspects of a person's life. Concerning the function of compliments, it is proposed that compliments in American English are mostly used for the fulfillment of the addressee's expectations, while compliments in Ecuadorian Spanish are frequently used to express a judgment. Because of these differences, it is suggested that compliments in Ecuadorian Spanish may be regarded by Americans as more direct and more intrusive. ${ }^{1}$

\subsection{Implicit compliments}

At the beginning of this chapter, it is argued that the study of the speech act of implicit compliments has been to some extent ignored (Herbert1997:488; Jaworski, 1995:65); while the previous studies presented above are dedicated to the explicit type of compliments, there are, to the best knowledge of the researcher, only three articles on implicit compliments. However, these studies discuss the topic under concern only from one perspective, namely, pragmatics.

\section{Ronald Boyle (2000) $)^{2}$}

In “'You've worked with Elizabeth Taylor': Phatic Function and Implicit Compliments," Boyle (2000:27) argues that there is a need to pay more

\footnotetext{
${ }^{1}$ Since the thesis is about implicit not explicit compliments, other related contrastive studies are not included such as the following: Billmyer, 1990; Chung-hye, 1992; Kryston-Morales, 1997; Lorenzo-Dus, 2001; Nakajima, 1996; Tang and Zhang, 2009; Zuo, 1988.

${ }^{2}$ The following studies are listed according to their relevance to the thesis, not chronically.
} 
attention to implicit compliments to reach a more balanced picture of this speech act and the neglect of the study of implicit compliments should not continue since the research focuses almost exclusively on explicit compliments, and implicit compliments are rarely considered. He argues that there are two reasons for this state of affairs, viz. the methodology commonly employed and the restricted view of the phatic function of compliments. The first is that "the methodology used by most researchers restricts the type of utterances that can be recorded to the short, the simple, the unambiguous, and the memorable (Boyle 2000:28);" therefore, the data are restricted to only the explicit type of compliments. This method is referred to as 'reduced' because, despite the rich and varied means of data collection, the human memory is considerably unable to keep all the linguistic and nonlinguistic clues related to the analysis of compliments. Boyle suggests that the audio- or video- recording of naturally occurring data has some merits over the human memory; "partly because the machine is not limited in the way the human memory is, and partly because tape-recordings and transcripts enable the researcher to reveal the complex, local, interactive institution of a compliment." (ibid)

It is not only the methodology used by most researchers which restricts the kind of data, but also the conventional view of phatic communion. Boyle (2000:20) indicates that "most researchers appear to have adopted a restricted view of phatic function of compliments, and have collected examples of 
compliments that reflect that understanding." He suggests that most researchers focus on the propitiatory function of phatic communion and neglect the explanatory one which "carries the conversational implicatures of negotiating a change in the relationship between the participants usually towards greater intimacy or greater distancing (Laver 1981:304).”

However, Boyle claims that there are two ways in which people say implicit compliments; the first involves referring to something that a person has accomplished and he or she is proud of (achievements of the addressee), and the recognition of this type depends heavily on indexical knowledge. The second involves comparing a person to someone that the speaker thinks the addressee admires. However, the attempt to constitute an implicit compliment may fail if the recipients do not identify the comparison as a positive one or if they are not satisfied with it. The claim that a compliment has been paid depends, in every case, on the examination of the indexical circumstances of the utterance and of the subsequent utterances. Therefore, Boyle uses an ethnomethodological approach to explain the interpretive procedures that people use to create a sense of intersubjective understanding. He refers to three of these procedures: indexicality, the documentary method of interpretation, and the reciprocity of perspectives.

Leiter (1980:107) explains the indexical knowledge or indexicality as follows: 
the conceptual nature of objects and events [...] without a supplied context, objects and events have equivocal or multiple meanings. The indexical property of talk is the fact that people routinely do not state the intended meaning of the expressions they use. The expressions are vague and equivocal, lending themselves to several meanings. The sense or meaning of these expressions cannot be decided unless a context is supplied.

Regarding the second procedure, the documentary method of interpretation, Garfinkel (1967:77, cited in Boyle, 2000:33) argues that a researcher depends on his background knowledge to analyze a given discourse; he embeds the particular instance in front of him in his presupposed knowledge of social structures and pays attention to the sequential unfolding of a course of action, and he waits for things to emerge and for things to become clear. The third procedure is the reciprocity of perspectives. Boyle (2000:34) suggests that despite the differences in our individual experiences and our objectives, we should see the world from the perspective of the other; therefore, a researcher should put himself in the position of the other to see things from that person's point of view. Finally, he concentrates on the fact that the aforementioned procedures should be used in the analysis of implicit compliments since they rely on the context for their constitution and effect. 


\section{Carmen Maíz-Arévalo (2012)}

In “'Was that a compliment?' Implicit compliments in English and Spanish," Maíz-Arévalo (2012:980) states that the current studies focus on explicit compliments and neglect the implicit ones; she suggests that the reason behind such treatment is the fact that "the first tend to outnumber the latter." Over four hundred compliment exchanges were collected (including both explicit and implicit compliments). Amazingly enough, less than $10 \%$ of these are implicit compliments. This preference of formulaic compliments over implicit ones might be related to the fact that speakers avoid too indirect compliments since the risk of not being correctly understood by the addressee is relatively high.

However, Maíz-Arévalo’s focus is not on the interpretive procedures used by interactants in a compliment event but on the pragmatic motives affecting the speaker's choice of this much rarer speech act. She makes interviews with some of the participants; the interviews support her discussion that people opt for implicit compliments in order to achieve two goals, namely, "avoiding facethreat (especially when distance is still relatively high between interlocutors), [and] wishing to sound sincere and/or building rapport (2012:994)." Unfortunately, Boyle's (2000) and Maíz-Arévalo's (2012) studies deal with implicit compliments mostly at the utterance level rather than at the discourse level. Consequently, the functions or motives provided above are social ones. 
This thesis would be a modest attempt to delve deeper into the compliment event to reach the interactional functions of implicit compliments.

\section{Silvia Bruti (2006)}

In "Cross-cultural Pragmatics: The Translation of Implicit Compliments in Subtitles," Bruti (2006) focuses on the strategic function of implicit compliments to evaluate their contribution to positive and negative politeness and their translation in interlingual subtitles (from English into Italian). That is to say, her paper aims to investigate the translation of some aspects relating to the texture of linguistic politeness in interlingual subtitling. However, the corpus of analysis is made up of various British/American films that have been distributed on DVD: Eyes Wide Shut, Philadelphia, Sabrina, Shallow Hal, There's Something about Mary, and Tootsie. She tries to answer two questions:

1- To what extent are these less formulaic speech acts successful with the addressees (i.e., speech acts that achieve the aim of creating good rapport and solidarity, or even, in some cases, some other more covert illocutionary aims)?

2- How are these implicit speech acts translated in interlingual subtitles? More specifically, if they are either simplified or altered, can the chosen translation be considered appropriate for the target language and culture?

Regarding the first question, Bruti argues that implicit compliments are more risky and costly since their interpretation depends on the shared 
knowledge between the interactants, but they are less face threatening since they attend to the needs of the addressee's negative face. Moreover, the complimentee tends to respond positively; that is to say, the addressee finds it less difficult to accept the content of the compliment as a fact. As for the appropriateness of the translation of implicit compliments in subtitles (the second question), Bruti notes that since the compliment response is entrusted to the iconographic code, the expression of praise is usually granted some space and is almost always fully retained.

However, in this chapter, the researcher explains that the speech act of explicit complimenting is extensively studied in the literature. Most, if not all, studies confirm Manes and Wolfson's (1981) findings that explicit compliments follow specific syntactic patterns and a limited number of lexical items, that is, semantically positive adjectives (e.g., nice, good, pretty, beautiful and great) and/or the verbs like and love. Moreover, studies on this speech act are conducted not only from syntactic, semantic and morphological perspectives but also from other perspectives, sociolinguistics and pragmatics. In many studies, it is explained that compliments are affected by many social variables such as gender, age, distance and power. And pragmatically, Pomerantz's (1978:81-82) suggestion that the recipients of compliments face an interactional dilemma; to accept compliments and avoid self-praise at the same time, is confirmed by many researchers. Moreover, contrastive studies have explored sociolinguistic 
and pragmatic factors that affect and justify the differences between speech communities.

While the explicit type of compliments is extensively studied, there are, to the best knowledge of the researcher, only three articles on implicit compliments. However, these studies discuss the topic under concern only from one perspective, namely, pragmatics. Boyle (2000:27) argues that the neglect of the study of implicit compliments is caused by two reasons: the methodology used in data collection and the conventional view of phatic communion. MaízArévalo (2012:980) suggests another reason behind such neglect which is the fact that explicit compliments tend to outnumber implicit ones (more than $90 \%$ of her data are explicit compliments). However, Maíz-Arévalo's focus is not (like that of Boyle's) on the interpretive procedures employed by interlocutors when receiving an implicit compliment but on the pragmatic motives underlying the speaker's choice of this much rarer speech act. Nonetheless, these two studies and that of Bruti (2006) relate the use of implicit instead of explicit compliments to the notion of face management, reducing the potential threat to the addressee's negative face. In doing so, they do not focus on the interactional functions that can be achieved at the time of the compliment event. The researcher argues that a better understanding of implicit compliments can be attained when this speech act is studied from a different angle unrelated to the theory of face. 


\section{Chapter Three}

\section{Methods and Procedures}

\subsection{Introduction}

In this chapter, the researcher states a simple review of the problem that needs to be tackled. Then, he provides the purpose of the study, the research questions and the significance of the study. Taking specific hypotheses into consideration, the researcher provides a thorough description of how the necessary data are collected, as well as the analytical procedure being used to draw conclusions. Moreover, the reader will be given an idea about the chosen variables and the limitations of the study.

\subsection{Statement of the problem}

The study of implicit compliments as a speech act has received little attention from sociolinguists as it appears in the previous chapter. Existing research, however, has focused almost exclusively on the collection of explicit compliments (Holmes 1988: 507), and it appears to have adopted a restricted view of the phatic function of compliments. Moreover, the study of the speech act of implicit compliments is conducted on Western societies and these studies discuss the topic under concern only from one perspective, namely, pragmatics. Therefore, this topic needs to be studied and conducted on Eastern societies and from different perspectives. 


\subsection{Purpose of the study}

Taking into consideration the previous problems related to the study of implicit compliments, this thesis is hoped to fill a gap and to lead to greater understanding of the topic since it is conducted on an Eastern speech community, namely, Jordanian Society. And also it utilized an interdisciplinary approach, i.e., the study examines implicit compliments from a sociopragmatic perspective. Being the situation as such, there is a room for improvement.

The study deals with the topic so as to find out the interactional functions of implicit compliments in Jordanian Arabic, Moreover, the study is hoped to shed a light on the influence of such variables as topic, participants, and setting on compliments. The study is also expected to refute the misconception that compliments have no functions apart from the social functions. It analyzes data extracts in order to show how implicit compliments are constructed and how they help the interactants achieve some linguistic and situational aims during or after the compliment event.

\subsection{Research questions}

As said earlier, this study attempts to investigate the implicit compliment speech act behavior of Jordanian people. To conduct this research from an empirical perspective, answers to the following questions are sought:

1. What are the topics of implicit compliments in Jordanian Arabic? 
2. What are the response types to implicit compliments in Jordanian Arabic?

3. What are the speaker's motivations/needs for an implicit instead of an explicit compliment (i.e. the interactional functions speakers try to achieve)?

4. What are the effects of social distance and age on the production of and the response to implicit compliments?

5. How is implicit compliment behavior affected by the context in Jordanian Arabic?

6. Can an implicit compliment be replaced by an explicit one in the same speech situation? If not, why?

\subsection{Hypotheses}

The study is based on the following hypotheses:

1- An implicit compliment is a systematic and rule-governed speech act.

2- Compared to explicit compliments, implicit compliments can be considered in some cases formulaic and in others nonformulaic; they do not have apparent semantic and syntactic patterns.

3- Implicit complimenting is correlated with some extra-linguistic variables (i.e., topic, participants and setting) as well as social variables. 
4- The motivations of using implicit compliments are completely different from those of explicit compliments.

5- Explicit and implicit compliments cannot be interchangeably used at the same time; replacing one type for another, if possible, would yield different results and different functions. Consequently, explicit and implicit compliments are not two different articulations of the same speech act, but rather they are two different speech acts.

\subsection{Significance of the study}

This research is significant to the domain of sociolinguistics and pragmatics as it extends the knowledge base that currently exists in that field. The concept of implicit compliment is relatively new to speech act studies not only in Jordanian Arabic but also in other varieties as well. Therefore, this research explores the topic area in order to raise awareness among those who are not acquainted with it. It is clear that previous research on the phenomenon of the speech act of implicit compliment has been limited. To the best knowledge of the researcher, there are only three articles on the topic. Boyle's (2000), Bruti’s (2006) and Maíz-Arévalo's (2012) articles are the only studies that investigate the topic under discussion. Moreover, the previous studies examine implicit compliments at the utterance level rather than at the discourse level; consequently, the functions or motives provided are social ones. This thesis would be a modest attempt to delve deeper into the compliment event to 
reach the interactional functions of implicit compliments. Thus, there is a necessity to conduct more in-depth data-based studies that will bridge this gap. The present study is intended to attain this goal by examining the speech act of implicit compliment used by Jordanian people within its larger context.

\subsection{Variables of the study}

Many social and cultural factors can be considered when a researcher studies implicit compliments. In the field of pragmatics and sociolinguistics, variables such as age, gender, education, race, power and origin have been common in studies on language use. However, the researcher chooses only two variables in his study, namely distance and age. Admittedly, these two variables are not the only ones which affect the compliment event; there are other variables as well which considerably influence the choice of implicit compliment over explicit one. However, the selection of distance and age to be considered as the variables of the study is caused by the ethnomethodological approach used in data collection; this thesis deals with the speech act of implicit complimenting, wherever possible, within its discourse since implicit compliments lose part of their meanings and implications if they are taken out of their context; considering the discourse within which this speech act occurs as a whole unit unfolds significant points about it, especially the complimenter's motivations for choosing implicit compliments to reach interactional functions. Being so, compliment events are tape-recorded and then analyzed. 
Returning to the parameters of the study, social distance is used most often as the main label for this dimension. Other terms are also used to refer to this variable such as solidarity, closeness, familiarity, and relational intimacy. However, Wierzbicka (1991: 105) proposes that:

Intimacy refers to a readiness to reveal to some particular persons some aspects of one's personality and of one's inner world that one conceals from other people; a readiness based on personal trust and on personal 'good feelings.

Therefore, Wierzbicka (1991:109) treats closeness/intimacy as a combination of mutual knowledge and mutual good feelings: "two people are said to be 'close' if they know one another very well, and have 'good feelings' for one another" (ibid). Kelley et al. (1983:38) propose that high interdependence is the key factor in a close relationship, and suggest that "the close relationship is one of strong, frequent, and diverse interdependence that lasts over a considerable period of time." In general, Spencer-Oatey (1996:7) suggests that researchers have variously interpreted distance as comprising one or more of the following (often overlapping) components:

1. Social similarity/difference (e.g. Brown \& Gilman 1960, cited in Spencer-Oatey 1996:7)

2. Frequency of contact (e.g. Slugoski \& Turnbull, 1988, cited in Spencer-Oatey 1996:7) 
3. Length of acquaintance (e.g. Slugoski \& Turnbull, 1988, cited in Spencer-Oatey 1996:7)

4. Familiarity or how well people know each other (e.g. Holmes, 1990, cited in Spencer-Oatey 1996:7)

5. Sense of like-mindedness (e.g. Brown \& Gilman, 1960, cited in Spencer-Oatey 1996:7). ${ }^{3}$

Regarding the other variable, namely, age, the researcher suggests that the role of this parameter needs to be taken into consideration since it has a considerable effect on the use of implicit compliments. Eckert (1997:151) explains that age and aging correlates with certain linguistic phenomena and shows some linguistic significance since they are experienced by individuals as well as speech communities. The study of age in relation to language, particularly the study of sociolinguistic variation, unfolds some significant revelations about the linguistic changes that take place through the individual's life span and the community as a whole. The individual speaker or age group of speakers at any given moment represents simultaneously a place in history and a life stage. Therefore, age stratification of linguistic variables can reflect change in the speech of the individual as he or she moves through life (age grading), and the speech of the community as it moves through time (historical change).

\footnotetext{
${ }^{3}$ There is no consensus at present among linguists concerning reliable ways of distinguishing close and distant relationships. Spencer-Oatey (1996:1) suggests that "authors often use the same terms with different meanings, or different terms with the same meaning, and that the parameters are rarely explicitly defined." Nonetheless, it is not within the scope of this thesis to provide a detailed discussion of this issue; therefore, social distance will be based on Wierzbicka's (1991:105) definition.
} 
However, what is relevant to the study of implicit compliments is 'age grading' since this thesis is synchronic in nature. The researcher treats 'age grading' as follows: life span is divided into different age groups; each group consists of ten years. Thus, two speakers (e.g., $\mathrm{X}$ is 32, Y 28) are said to belong to different age groups, since one of them is in his thirties and the other in his twenties respectively.

\subsection{Data collection}

Golato (2003) provides a detailed study of the differences between compliment responses collected with two different data collection procedures: naturally occurring data analyzed through conversation analytic (CA) methodology, and elicited data collected via a discourse completion task (DCT). The DCT is designed to evoke the same discourse context and preceding co-text observed in the naturally occurring data. Throughout the article, she discusses some data collection procedures including questionnaires, recall protocols, role play, field observation and recording of naturally occurring talk-in-interaction. She argues (2003: 91) that "many studies of compliments and compliments responses do not, in fact, cannot, describe actual language use, simply because their analyses are not based upon data that illustrate actual language use with sufficient granularity."4

\footnotetext{
${ }^{4}$ In addition to the example studies provided by Golato (2003) in her article, all studies mentioned in the previous chapter are not based upon data collected via recording of naturally occurring talk-in-interaction except Boyle (2000) and Maíz-Arévalo's (2012) studies.
} 
Moreover, she (2003: 110) suggests that "if one is interested in finding out how speakers react to compliments in real-time interaction, if one wishes to discern the underlying interactional rules and patterns $[\ldots]$, then DCTs are inappropriate." She, then, recommends audio- or video- taping of naturally occurring data. Such a method enables the researcher to investigate "how speakers are using language to create meaning" and "how certain speech events are organised in their natural settings" (ibid).

Based on the previous justification, the researcher prefers and chooses the ethnomethodological approach for data collection. The data consists of nonelicited, audio-taped face-to-face encounters and spontaneous conversations. The strength of CA lies in the fact that "its methodology allows for the repeated and detailed analysis of utterances in their sequential context" (Atkinson and Heritage 1984:4, cited in Golato 2003). Thus, the researcher can study the linguistic structures as they used in real life and in real time. Moreover, taperecording of conversations enables the researcher to incorporate every element in the interaction (hesitations, laughter, silences and the like) in his analysis.

\subsection{Data analysis}

The relationship between social variables, viz., age and distance, and participants' preferences for implicit compliments and choosing certain response strategies can acquire trustworthy examination by means of analyzing the discourse in which the speech act of implicit complimenting occurs. To be 
more specific, the interactants' selection of this type of compliment and their response strategies are the dependent variables and the independent variables in the present study are age and social distance.

Through the results of this analysis, the researcher can determine whether there are significant differences between the occurrence of implicit compliments and participants' age and the distance in their relationships. The analyses also help him ascertain whether participants' preferences for implicit compliments would display significant interactional functions that cannot be achieved through the use of explicit compliments, bearing in mind that both types of compliments, to some extent, have the same social functions. In general, the researcher treats the compliment event as a unitary discourse whose analysis hopefully unfolds important points and ultimately helps the researcher answer the research questions. That is, the analysis of implicit compliments relies on the context for their constitution and effect.

The investigation of implicit compliments in their natural discourse contexts helps the researcher appreciate the interrelations of semantic phenomena. He attempts to analyze the separate kinds of referential, ideational, interpersonal, and intended meaning. He bases his analysis on recording transcripts representing the recorded speech situations. After recording the conversation using Sony Ericsson wt13i mobile as a recording device, the researcher immediately sits down to do a draft transcription to make sure that he 
still remembers all the contextual information that helps him interpret blurred or unclear words or passages.

Moreover, he presents the examples with a brief statement of relevant contextual information to help analyze and contextualize them. And this way of providing the context of each example is especially important for the material since most, if not all, cases depend on reference and context to express meaning. Following Halliday and Hassan's (1976, cited in Maíz-Arévalo 2012:982) notion of "context of situation", the researcher precedes each example in the study by as much contextual information as possible about the field (what the interactants are doing at the time of the dialogue) and the tenor (who are the participants and to what extent their relationship is close). The mode (kind of language used, oral or written, etc.) has not been taken into account since all the exchanges are oral.

\subsection{Population and sampling}

\subsubsection{Population}

The population of the study consists of all native Jordanian Arabic speaking people living in Irbid city, Jordan.

\subsubsection{Sampling}

Maíz-Arévalo (2012) states that the current studies focus on explicit compliments and neglect the implicit ones; she suggests that the reason behind 
such treatment is the fact that "the first tend to outnumber the latter (2012:980)." She collects over four hundred compliment exchanges (including both formulaic and implicit compliments) and finds that more than $90 \%$ of these compliments are explicit ones. However, the researcher, to a great extent, agrees with Maíz-Arévalo (2012) since he finds that implicit compliments rarely occur in conversations, consequently, the researcher cannot choose the persons who would represent the population of the study. He is enforced to audio-tape compliment events wherever and whenever they occur. Audio-taped compliments may occur within any activity that Jordanian people are normally engaged in. Such activities may take place within indoor or outdoor settings (at home, school, market, and the like). Interlocutors are from the lower and the middle class; they occupy different positions (for example, sales people, customers, teachers, school/ university students, managers, workers, etc.). Interactants ranged in age from 5-60 years, with the majority being in their twenties and thirties. All of them live in Irbid city or its villages or camps. Nevertheless, the random sampling technique is used to obtain the sample of the study. The researcher randomly selects the subjects from Irbid City.

\subsection{Limitations of the study}

This study is limited in four ways:

First, it will look at utterances in normal situations by recording natural talk-in-interactions. This method of collecting data has been criticized because 
the corpus is too small to make certain generalizations, and other methods are preferred such as discourse completion task (DCT). However, in a previous section, the researcher explains why data collected via DCTs are inappropriate for the study of implicit compliments (see 3.6. Data collection). In addition to reasons mentioned above, other justifications are easy to be stated; Golato (2003:110) observes that "subjects complained about the DCT while filling out the questionnaire, saying that they felt funny and it was hard to imagine what one would say."

Moreover, she (2003:111) argues that "DCTs are better suited to the study of 'what people think they would say' than the study of 'what people actually do say' in a given speech setting." Therefore, DCT is inappropriate for the study of implicit compliments. Recording naturally occurring conversations is more suitable and necessary since it helps the researcher to focus on the constitution and effect of compliments and compliment responses. Secondly, the study is based on a small set of data which is hoped to be enough to reflect the Jordanian methods of complimenting and responding to compliments. This restriction is justified on practical grounds since limiting the scope of the research will help the researcher arrive at more reliable findings since he studies the compliment event at the discourse level. Third, the study focuses only on two social variables, namely, age and social distance. Other variables such as gender, ethnicity, religion, status, etc., are not considered. The fourth limitation 
is that the thesis is concerned only with dialogic, oral and spontaneous discourse. Other types of discourse, such as pre-planned oral discourse (e.g., interviews on television or radio), monologic (e.g., diaries) or dialogic written discourse (e.g., ceremonious compliments at birthdays and other special occasions) are not included. 


\section{Chapter Four}

\section{Findings and Discussion}

\subsection{Introduction}

Following the methodology explained in the previous section, the researcher discusses the speech act of implicit compliments in Jordanian speech community from a sociopragmatic perspective. In this chapter, implicit compliments are divided into several subheadings according to the definite categories under which they are found to occur. The speech act under concern is found to be related to two major categories, viz. formulaic and nonformulaic, and each category is divided into different minor classifications as explained throughout the chapter. However, the researcher discusses each example in a thorough way to provide appropriate answers for the research questions.

\subsection{Formulaic implicit compliments}

Beyond the level of the utterance, the study of implicit compliments reveals the fact that there are social and interactional factors that seem to be the key to understand the construction and structure of Jordanian implicit compliments. These factors can be divided into social and interactional ones; there are social factors such as distance and age which affect and limit the occurrence of the compliment event. And there are interactional factors such as topic, participants, and setting which also determine the timing of the 
compliment, and consequently, the interpretation and acceptance of it by the interactants. Therefore, linguistic and social features of implicit compliments are explored in order to reach a better understanding of the effect of these factors.

However, the discussion of the functions of compliments has been centered in previous studies on the social purpose, namely, to create or maintain harmonious relationships. Compliments have been claimed to function as "social lubricants" which "grease the social wheels" (Wolfson 1983:89). Knapp et al. (1984:12) also report that "some people believe compliments are as critical to social success as oxygen is to breathing." The researcher claims that such a narrow view is not satisfactory since many interactional functions are accomplished by this speech act. According to Papi (2009:140), the discussion of implicitness phenomena includes not only the propositional contents but also “aspects of meaning resulting from speakers' attitudes and emotions, as well as aspects of the (even non-intentional) effects an utterance may have on the hearers and their interpretations."

Moreover, the researcher argues that implicit compliments, in some cases, are formulaic/idiomatic in the sense that there are some words collocated in a certain way to mean approval or appreciation; some word clustering yields fixed or semi-fixed phrases used as implicit compliments. To support his suggestion, the researcher provides two sections; the first one includes authentic 
situations in which fixed expressions are used as implicit compliments (a Jordanian reader can remember how often such expressions are used in this way so he/she can judge the plausibility of the argument). The second section includes situations in which implicit compliments are found to follow fixed syntactic structures, viz. interrogatives and exclamatory declaratives ${ }^{5}$.

\subsubsection{Implicit compliments as idiomatic expressions}

Implicit compliments require more inference work for the addressees to reconstruct these ambiguous utterances as compliments - the participants would need to rely on the interpretation of contexts (Brown and Yule 1983: 33). Such a view renders implicit compliments as nonformulaic speech acts. Moreover, this belief is confirmed in Boyle's (2000) paper; she (2000:35) suggests that there are two ways in which people say implicit compliments; the first involves comparing the addressee to an admirable person. The second involves referring to the achievements of the addressee. However, a compliment, in every case, depends on the examination of the indexical circumstances of the utterance and of the responses displayed in subsequent utterances. Consequently, Boyle (2000) does not mention any idiomatic expressions used as implicit compliments since she considers this type of compliments to be nonformulaic in

\footnotetext{
${ }^{5}$ The researcher agrees with Stubbs (2001:301) that frequency, probability, and norms as characteristics of language use can be studied only with quantitative methods and large corpora, but the absence of large corpora leads the researcher to depend on his background knowledge and assumptions in his discussion of the idiomatic expressions given under this section. The researcher cannot be sure to what extent these expressions are frequent and the whole issue will be negotiable till it is studied with quantitative methods and large corpora.
} 
all cases. Such a view cannot be generalized to other languages. Maíz-Arévalo (2012: 994) states that

some implicit compliments may not be that implicit after all, but repeat the same patterns _ even their linguistic realization _ both in English and in Spanish. This leads us to argue for a cline of explicitness when dealing with compliments, ranging from the most formulaic types (e.g. what lovely eyes!) to those based on implicatures more difficult to decipher.

However, the researcher supports Maíz-Arévalo's (2012: 994) findings since the data collected reveal two ways in which implicit compliments are rendered formulaic, viz. implicit compliments as idiomatic expressions and implicit compliments as formulaic structures. This section is devoted to the first type, namely, idiomatic expressions interpreted as implicit compliments. In what follows, the researcher argues that certain idiomatic expressions can be interpreted in two ways; the literal, out-of-context meaning which has nothing to do with complimenting, and the expressive, implied meaning which depends on the context to be interpreted as complimentary (the context determines the use of the expression to be related to the speech act of compliment not to another speech act). Consequently, in sharp contrast with explicit compliments, implicit compliment in the form of idiomatic phrases cannot be word-for-word translated and have their intended illocutionary force. 


\section{Example 1}

[Field: A geography teacher who has bought new trainers is walking in the playing yard with another teacher; students are sitting nearby eating and talking during the break.//Tenor: $\mathrm{S}$ (male, 15) is one of the students whom $\mathrm{T}$ (male, around 34) had taught two years ago. The relationship between them is not friendly at all since $\mathrm{S}$ is a mischievous and troublesome boy].

1. S: wallah qaaSdak bhalbooT.

2. 'By God, can you lend me your trainers?'

3. T: imqaddam

4. 'You can take it whenever you like' ((irritated, walking away without waiting to hear the response)).

In Jordanian dialect, when somebody says qaaSdak bhal (certain item), the hearer deduces that the speaker admires the item in question. This expression is fixed in this way as a compliment (with some exceptions related to different contexts). However, the usual response would be 'imqaddam' or '9ala Hsaabak,' such responses would not be taken literally, for the simplest reason that the speaker is not serious and in most, if not all, cases is unwilling to give up the object. In the example above, the trainers are not of the right size for $\mathrm{S}$ since he is a small boy and the trainers are of a big size; therefore, the request and the reply are meaningless and serve no function except that of 'a small talk.' 
The usual response of implicit compliments (as most cases reveal) is acceptance in some way or another; $\mathrm{S}$ tells $\mathrm{T}$ that he likes his appearance (specifically, the new trainers) and receives an angry response. $\mathrm{T}$ unwillingly accepts the compliment and unconsciously sticks to the usual response. Taking into account the distant relation between $\mathrm{S}$ and $\mathrm{T}$, the timing of the dialogue and T's background knowledge about $\mathrm{S}$, it becomes clear why $\mathrm{T}$ takes the compliment as a sarcastic one although it is not. Sociolinguistically, two main factors are fundamental in providing social explanations for this situation; namely, social distance and age. Firstly, T, being a teacher, maintains a linguistic, pedagogic and disciplinary control; therefore, he has a higher power over the student. The social distance between $\mathrm{S}$ and $\mathrm{T}$ is high since their relation is that of high-power and low-solidarity, and that increases face-threat for both. Belonging to different age groups, $\mathrm{S}$ (15 years) and $\mathrm{T}$ (34 years) would have interaction problems and communication difficulty which cause the preference of indirectness.

However, the use of certain expressions in this way can be considered as implicit compliments since there are no positive verbs (e.g., love, like) or positive adjectives (e.g., lovely, beautiful and great), (for a detailed discussion, see 1.1. What is a compliment?); this example as well as other ones lead us to refute the given argument that implicit compliments are in all cases nonformulaic. 


\section{Example 2}

[Field: $\mathrm{A}$ is desperately searching for a change, $\mathrm{S}$ is sitting in his store.//Tenor:

A (male, around 30) and S (male, around 35) are neighbors, but they do not have any relation at all]

1. A: ma9ak Srafit 9ašara ?

2. 'Do you have a change for 10 dinars?'

3. S: ah (0.9) ta šo:flak yallah (2.1) laqaytlak!

4. 'Yes let me see I have. (( he gives him the change))

5. A: ah hayk (0.3) Sa:r ma9i (0.2) 9išri:n

6. 'Now I have 20 dinars.' ((he did not give him the 10 note, jokingly))

7. $\mathrm{S}:$ gaHsaabak.

8. 'You are worthy of them' or 'it makes no difference.'

9. A: allah yis9idak.

10. 'God bless you.' ((thanking))

11. S: tislam.

12. 'Thank you.'

In this case, we return to the idea of fixed expressions utilized as implicit compliments (cf. the use of qaSdak b-hal-(certain item) and "imqaddam" in example 1). To illustrate the idiom from this angle, we can say that $\mathrm{S}$ was surprised by the unexpected joke, so he searches his memory for a quick reply; the most appropriate one should be a fixed item that the speaker has frequently used in similar situations. A's joke provokes a friendly response because of two factors: firstly, A uses the joke to create rapport and that is evident in his smile 
as well as his intonation. Secondly, A is in power at that moment when he has the 10 note and the change.

Returning to S's response, the researcher suggests that one of the reasons for choosing an implicit over explicit compliment is the verbalization problem; Chafe (2001:679) states that "language cannot fully or adequately express an inner experience. The verbalization process allows a speaker to get a useful handle on the experience and share it to some degree with others, but the linguistic organization of ideas is not the same as the experience itself." This situation is caused by the limited resources a language provides for verbalizing an individual's experiences and thoughts.

Therefore, in certain situations the speaker does not have the appropriate lexical items to express his thoughts, so he uses gestures, hand movements or/and some markers of insufficiency. Such markers are used to provide the speaker with a sufficient time to form a meaningful message. In this example, the fixed item ' $9 a$ Hsaabak' serves the previous function in addition to the function of problem solving; $S$ avoids a potential problem for if he had behaved in another way, a problem would have emerged ( at least A would be angry and will not return to S's store and S will lose one of his customers). Therefore, implicit compliments are not always used phatically.

Regarding sociolinguistics, the main factors under concern, namely, social distance and age, influence the choice of implicit compliment as follows: 
A, having the 10 note and the change, has higher power over the store owner because at that moment $\mathrm{S}$ needs $\mathrm{A}$, this increases the social distance between $\mathrm{A}$ and $\mathrm{S}$ and makes it higher since their relation is similar to that of strangers. Referring to the interlocutors' age, there is no significant role of the age variable in this case since A (30 years) and S (35 years) belong to the same age group.

\section{Example 3}

[Field: A, a laundryman, is doing the ironing; D comes to the laundry as a customer.//Tenor: A (male, around 40) meets D (male, around 25) for the first time; they do not know each other]

1. D: issala:m 9alaykum.

2. 'Peace be upon you.'

3. A: wa 9alaykum issala::m, hala Habibi hala beek hala beek.

4. 'And peace be upon you, welcome, my dear, welcome, welcome.'

5. D: wallahi 9indi banTalunay:n biddi ?aaji akwiihum.

6. 'I want you to iron two pairs of pants.'

7. A: 9ala Tu:1 si:di.

8. 'I'm at your service, sir.'

9. D: qaddayš tu?murni 9alayhum ?

10. 'How much?'

11.A: ?mayt biddak yahum ? 
12.'When do you want them?'

13.D: 9a:di ?amayt ma yijhazu, miš mista9jil 9alayhum.

14. 'Take your time-there's no hurry.'

15.A: $\theta$ amaniin qirš.

16. ' 80 piasters.'

17.D: ya zamih ?ana bakuihum b?aql wallah 9ind maHal $\theta$ ani=

18. 'Oh man, I can have them much less than you ask.'

19.A: 9aHsabak wallah Habibi (1.2) bala maSa::ri.

20.'If you like, I would do them for you for free, without money(on my bill).'

21.D: Tayb ra9ina ya zalemeh ra9ina ( ).

22. 'Oh man, a little deduction will be okay, please, deduct the cost a little 23. bit further'

24.A: wallahi ya Habibi ya9ni (1.2) bidak tiHsibha 9allaqa::t 9alaqa wkees

25. wkaða=

26. 'You need to think of the expenses; hangers...a hanger, a bag and other

27. things.'

28.D: ?ana ma9ak bas wallahi: ya9ni:: waZ9i ya9ni:!

29.'I understand, but, By God, well, my position (not having enough

30. money), well.'

31.A: taklufitha 9alayna \a:lia. 
32. 'The expenses are really high.'

33.D: Tayb yallah sab9iin mli::H ?!

34. '70 (piasters) would be okay?!'

35.A: 9aHsaabak (.) miš faarqa. (( lowering his voice))

36. 'You can have them for free, it makes no difference.'

37.D: allah yis9idak allah yis9idak. ((pleading))

38. 'God bless you, God bless you'

39.A: ((no response))

40.D: $\underline{x a l a S}$ ittafaqna sab9iin qirš.

41.'Let's make a deal, 70 piasters'

42.A: la? Ma biSiir hayk (.)?ana si9ri wa::Had 9alkul (0.3) si9ir muaHHad.

43. 'Do not argue with me more. I have a fixed price, for all customers.'

44. D: ?ana bakwiihum ib?aqal min hiik.

45. 'I can have them much less than you asked.'

46. A: xalaS xaliiha 9alay ilmarra hay[D: ?allah yis9idak.] la?inaak ?awal

47.mara btiji 9alayyeh [D: ?allah yis9idak.] w9ala Hsaabi wxallina niksabak

48. ibfunjan qahweh [D: ?allah yis9idak bil?afraaH in ša:llah.] billaah

49. 9allayk[D:?allah yis9idak ?allah yis9idak]=

50. 'Let me do them for free this time' [D: 'God bless you, God bless you.'

51. ((thanking))] 'for your eyes, this is the first time you come' [D: 'God 
52.bless you.' ((thanking))] 'let me pay the expenses, let's drink coffee' [D:

53. 'God bless you (thanking), at wedding ceremonies, God's willing']

54. D: ya9ni hayk ?aaxir si9ir 9indak.

55. 'This means you've made your mind.'

56.A: ?a:xir si9ir wallah ya Habiibi (.) ?axir si9ir.

57. 'Deduction is impossible, dear, it is the last price.'

((Feeling that $\mathrm{D}$ is not yielding, A draws back and accepts ironing two pairs of pants for only 70 piasters)).

In example 2, it is argued that there are certain expressions used as implicit compliments according to their context. And it is claimed that they serve different functions: solving the verbalization problem and avoiding potential problems. In example 3, implicit compliments are used for other purposes. In the previous situation, it can easily be noticed that arguing with a stranger in order to reach an agreement, especially about the price of something, is unbearable; compliments are used in such interactions to make them smoother and easier so an agreement can be reached. The dialogue above exemplifies this function and leads us to think of implicit compliments from a different angle; in the case under consideration, the laundryman is not sincere (like most smarmy salesmen) in his repeated offers to do ironing for free. The words in italics '9aHsaabak... bala maSari' and 'xaliiha 9alay' have many implications. The first one could be as follows: 'please, do not think of me as a 
greedy person; money is nothing to me,' and this meaning renders the compliment as self-praise. The other implication could be deduced as follows 'you are more important than money, you are a worthy customer and you deserve all respect and admiration.'

However, both implications are not applicable because the laundryman does not sincerely intend them and the complimentee does not willingly accept them. The refutation of the first implication is not difficult to be done; when the customer asked about the price (lines 9 and 10), the laundryman escapes the answer by pretending that he is busy; he asked the customer if he is in a hurry or not; this pretense contradicts his earlier statement (lines 7 and 8) that suggests his readiness to do ironing at any time. Such behaviour enables the speaker to form a convincing statement about the price. Moreover, each mention of '9aHsaabak' or 'xaliiha 9ali' is followed by an elaboration of the impossibility to make any deduction and the last mention of these positive words is followed by a desperate try of more haggling on the part of the complimentee.

The inapplicability of the second implicature can be justified as follows: throughout the discourse the laundryman faces the haggling with a stubborn resistance to iron the two pairs of pants less than 80 piasters. Moreover, the idea of the worthiness of the customer had been completely erased when the laundryman states that he has a fixed price, for all clients (lines 42-43), therefore, the customer is not special in any way. In short, the two implicatures 
are not applicable at all, and implicit compliments used in this case and in other similar cases are ostensible ones. Returning to their functions, they serve two aims: the first one is that of creating a smooth atmosphere for reducing stress in certain interactions. The other one would be that of supporting the speaker's high self-esteem (contradictions like that explained before do not weight for the simplest reason that they negatively affect the addressee, but for the speaker they help him to stay in his present power and consequently maintaining his self-worth). However, in support of the previous argument, Stubbs (2001:312313) states that "frequent collocations allow a hearer/reader to make predictions about the surrounding text $[\ldots]$. In terms of cultural competence, culture is encoded not just in words which are obviously ideologically loaded, but also in combinations of very frequent words." Therefore, it is plausible to make logical predictions about the interactants' (un)conscious intentions and attitudes in the compliment event in order to reach a better understanding of the discourse.

As stated in previous examples, two main factors, namely, social distance and age, influence the preference of implicit compliment as follows: D, being the customer, has a higher power over A, the laundryman, since A needs D more than D needs A; the customer can go to any store and have nearly the same service quality, but the store owner cannot choose his customers. Consequently, D is the receiver of the verbal gift. The social distance between A and $\mathrm{S}$ is affected by the previous consideration; therefore, the distance is high 
since they do not know each other. Referring to the interlocutors' age, age plays a significant role in this case since A (40 years) and S (25 years) do not belong to the same age group. Unlike example 1, in which the student indirectly compliments the teacher, here the higher in the age scale compliments the lower. Such a finding leads us to suggest that implicit compliments occur from the younger to the older or vice versa more frequently than they occur between two speakers of the same age group.

\section{Example 4}

[Field: $\mathrm{M}$ is talking to his friend $\mathrm{D}$ over the telephone.//Tenor: $\mathrm{M}$ (male, around 30) meets D (male, around 26) frequently and they have a close relationship]

1. M: kay:f Haalak ?

2. 'How are you?'

3. D: miš naqiSni Viir šooftak

4. 'Seeing you will complete my well-being.'

5. M: ?allah yis9idu

6. 'God bless you.' ((thanking))

Compared with the aforementioned examples, this case is less widespread. The expression miš naqiSni Yiir šooftak is used among friends or relatives who have intimate relationships. The restricted use reduces its applicability, but, it is frequently utilized. Such an expression is considered an implicit compliment because it carries the following implication: 'you are my sheer joy,' or 'you are the cause of my happiness since you are qualified to be 
so;' these meanings render the expression to be analysed as a compliment and M's response reinforces such understanding; M appreciatively thanks D for his cordiality.

The use of this expression is restricted not only to intimate relations but also to limited situations; its most occurrences appear during telephone conversations since the interlocutors are not in visual contact, and consequently unable to see each other, and most cases of this expression occur at the beginning of the dialogue. Nonetheless, the expression is likely to occur in face-to-face communications, and these rare occurrences make us question its purpose. Why doesn't the speaker directly express his compliment if the primary purpose of this speech act is to maintain a harmonious relationship? Since both implicit and explicit compliments have the same social function, there would be another purpose; the researcher supposes that the function is related to the economy principle ${ }^{6}$ (to borrow a term from syntax, of course with a slightly different application). The claim here is that speakers in general prefer reducing two sentences to one sentence: the sentence can be divided into two parts, miš naqiSni which is the theme of miš naqiSni iši alHamdu lillaah 'I am in perfect health and happiness, thank God'; this reading is related to the most frequent reply in similar phatic talks, and Viir šooftak which is the rheme of $m a$ biddi Yiir šooftak 'I need nothing except seeing you (I missed you).' Combining

\footnotetext{
${ }^{6}$ Papi (2009:160) relates the use of implicitness in natural languages to the fact that "the mind tends to obtain the maximum with the minimum effort[...] as a way of simplifying and speeding information processing." Therefore, implicitness is used "to favour- not to hinder- the functioning of the mind."
} 
two sentences in this way is beneficial to both of the interactants since it takes shorter time, bearing in mind that most occurrences of this expression happen during telephone conversations.

As pointed out in the previous examples, two main variables, viz., social distance and age, affect the preference of implicit compliment as follows: the compliment would be more frequently utilized between non-intimates and between different age groups than in other cases. At the first glance, the previous assumptions would not hold; the interlocutors in this example are intimate friends who meet frequently. However, a closer examination of this case may enable us to draw the different threads together in the following manner: based on our world knowledge, we can suppose that $\mathrm{D}$ who initiates the telephone conversation is in need of $\mathrm{M}$ for some purpose (as human beings, we have motivations for our actions). So, D is responsible for giving the verbal gift. Bearing in mind this assumption and that $\mathrm{M}$ (around 30) and $\mathrm{D}$ (around 26) belong to different age groups, the social distance between interactants is not affective in this case. ${ }^{7}$

\section{Other idiomatic expressions}

* Other fixed expressions used as implicit compliments can be found in every day communication, more clearly on special occasions such as the following:

\footnotetext{
${ }^{7}$ Although the social variables in the previous examples are effective, the researcher hypothesizes that the use of idiomatic expressions understood as implicit compliments is not always affected by the social variables; their construction is related to interactional functions that interlocutors need to achieve.
} 
Case (1): ?allahummah Sallii 9annabi, ma: ša:: ?allah 'Allah's blessings be on the prophet, God has willed it' is utilized as a compliment when the addressee shows the speaker his/her new born infant, modern car, spacious apartment, etc. The speaker uses this form to evade appearing envious or jealous; if the speaker explicitly compliments the addressee without mentioning Almighty God or praying upon His Prophet (Peace and Blessings be Upon Him), a misunderstanding might take place. In other words, direct compliments are not preferred in such situations. Nonetheless, if the speaker likes to give one, implicit compliments should precede it. Otherwise, the speaker would be mistaken and, consequently, prone to criticism.

Case (2): na9iiman 'Bless you! or cheers! is used to compliment the addressee after having either a bath or a haircut. In both cases, it has the positive implicature 'your appearance is really attractive,' the addressee, saying allah yin9am 9alayk, thanks the speaker for his cordiality. However, this expression can be used sarcastically in situations when the speaker utilizes it to criticize the addressee who is absent-minded during a conversation. In such a case, the speaker uses the expression to suggest that the addressee is not following the conversation and he does not know what the speaker is talking about. Therefore, it is safe to say that this expression is context-bound.

Case (3): yislamu ?idayk(i) '(May God) bless your hand' or da:ymeh 'may yours be an everlasting table' is employed as a compliment after having a meal 
or drink. This expression could have the following implicature 'the meal/drink is really delicious and tasty (and I do not need more, thank you).' Explicit compliments in this situation could provide unintended connotations such as 'the food is delicious, so I need more.' The distinction between the two situations can be clearly noticed in the addressee's response; in the first case, the response would be an ostensible invitation, but in the latter it would be a genuine one. However, the use of this form serves as an expression of gratitude.

Case (4): miš bin(at)na miš muškilih 'no problem' is used as a compliment when there is an argument over something shared between the interactants, especially money. The giver of this gift, mostly unwillingly, opts for this form in order to make a mutual concession. The speaker compromises with the addressee so that he/she can achieve two purposes: appearing more generous than the addressee (maintaining self-esteem) and reaching quickly for an agreement (avoiding potential conflict).

Case (5): yallabt-aklik 'I've troubled you' is employed as a compliment when the speaker has asked the addressee to do something which is not of his/her business. This form has the following implicature: 'you have accomplished the task successfully, thank you'. In doing so, the speaker delivers two messages, namely, the expression of satisfaction and that of gratitude, in one phrase (the economy principle). A note should be explained here, the theory of facemanagement has nothing to do with this form because it is utilized after the 
demand, and so neither the speaker nor the addressee's face would be threatened. To illustrate this suggestion, we can differentiate between Vallabtak and biddi ?a Yalbak. The latter is used before a demand; therefore, the theory in question can be applied to it since it is utilized to minimize the imposition and has used to deliver only one message which is 'please' or 'would you mind if ...?'

Case (6): winnigim 'with respect' is used by the complimenter to indicate his admiration and approval of the addressee's clan. This form can be interpreted as 'your family is respectful and venerable.' The addressee, in most cases observed, thanks the speaker saying winnigim minnak to provide a similar implicature 'your family is also respectful and venerable.' However, this phrase is usually used after asking private questions about the complimentee's family, thus, this phrase serves the function of showing admiration and gratitude; the speaker implicitly thanks the addressee for his cooperation and answering private questions instead of rebuking the speaker who appears nosy.

Case (7): haTTah iSba9ik fiiha 'you've put your finger in it' is used to compliment the hostess or the doer of a drink (usually coffee or tea). This form has the following implicature: 'the drink is sweet and tasty.' Therefore, this phrase serves as an expression of thanks.

Case (8): rijlak xaDra 'your leg is green' is used on many occasions especially in stores by the sales person to compliment the customer who attracts 
other customers to the store ( or by the customer to draw attention to himself/herself and this implicit self-compliment will be beneficial later on at the moment of haggling). This expression implies the following statement: 'you/I bring goodness wherever you/I tread.' However, the compliment serves the function of expressing gratitude if it is used by the sales person, or it serves the function of paving the way for haggling or giving a reason for a deduction if it is used by the customer himself/herself.

Case (9): qalbak ?abyaD 'your heart is white' is used in situations when the addressee has the right to behave maliciously against somebody. The complimenter provides this expression to remind the addressee of his/her noble traits. However, it indicates that the complimentee cannot bear grudges against anyone. The speaker implicitly compliments the hearer in order to reduce stress in a difficult situation (nonetheless, this expression is applicable in other nonstressful situations as well).

Case (10): wijhak willah Daw ilqamar 'is it your face or the light of the moon?' is an idiomatic expression of compliment since it is a semi-fixed phrase which is used to hide the speaker's surprise; the complimenter utilizes this phrase at the beginning of a discourse to mask his/her feeling of surprise (and possibly other feelings such as happiness, disappointment, and excitement); the complimentee depends on the speaker's intonation and the subsequent dialogue 
in order to specify which feeling s/he is trying to hide. The benefit of using this expression is to create a friendly atmosphere for the coming speech event.

Case (11): nourak kifayeh or imnawreh biwjoodak 'your light is enough' or 'it is lit by your presence' is frequently used on many occasions especially when the discourse topic is shifted to the mention of darkness, the complimenter utilizes one of the expressions above to end up an unpleasant sub-topic and to reduce the effect of the complaint. By and large, the implicit compliment here serves the function of avoiding potential problems.

Case (12): min zamaan ma kaHHalit 9ayni ibšouftak 'to my eyes, seeing you has the same effect of an eye-liner (for a long time, I have not seen you).' The speaker uses metaphor to express his yearning and desire to see the addressee; in this metaphor, the complimenter likens the importance of seeing the addressee to his spirit to the effect of an eye-liner to his eyes. In Arabic culture, eye-liner makes the eyes not only more noticeable and attractive but also healthier since it has positive aesthetic and medical effects. Therefore, this expression may follow the economy principle since it provides two messages in one utterance.

Case (13): ?idak xafifeh 'your hand is light' is utilized to compliment a barber, for example, after doing a haircut, this expression indicates that the movements of the barber's hands are skillful, and consequently, this phrase serves the function of expressing thanks. This collocation is used restrictedly with workers 
after doing some activity, and in other contexts it has negative connotations; it means sleight of hand about the hand movements of thieves, for example.

Case (14): dammak xafiif 'your blood is light' is used to imply the following: 'you're fun to be around.' This expression is utilized by the complimenter to indicate that after telling an unbelievable story, the addressee is not telling the truth, it is just a matter of exaggeration. Therefore, this phrase is used as an indirect criticism.

Case (15): ?9Saabak baardeh 'your nerves are cold = you can take a grip on yourself' can be used to compliment the addressee on his patience in a difficult situation; the complimentee in such a situation can control his emotions although he is afraid, upset or angry; consequently, he is able to behave sensibly and logically.

Case (16):?iidak Taayleh 'your hand is stretched out' is utilized to compliment a powerful person with good connections who can illegally solve problems by taking the law into his hands. This implicit compliment may be used as a preparatory phrase for a request within the same discourse or after it.

Case (17):?intah faSSil wana balbas 'you sew and I wear' implies that the speaker respects the addressee too much to the extent that he cannot reject his decision; the complimentee is an admirable, wise person who is able to take the 
right decision. Therefore, this expression serves the function of nonnegotiable, indirect acceptance.

Case (18): ?ibin 9aalam ?unaas 'son of world and people $=$ son of righteous people' is used to compliment the addressee by referring to his parents. This phrase carries the following implicature: you are a respectful person and this is due to your ethical raising. Therefore, this expression may be used as an expression of thanks; the speaker shows his gratefulness to the addressee for doing the right thing in a situation where the addressee can behave maliciously.

Case (19): min il?aaxir 'from the end' is used to imply that the complimentee is deserving all respect since he is a great person. The specific meaning of this phrase can be determined only from the context; if the discourse topic is related to generosity, the expression would mean that the addressee is a generous person. If the topic is about courage, the addressee is courageous and brave. If it is about beauty, the addressee is a handsome person. Therefore, this expression may be said to solve the verbalization problem. However, this phrase is used among the youth, especially adolescents, more than among the old.

To sum up this section, it has been claimed that idiomatic expressions are used as implicit compliments, in contrast to the view provided by previous researchers that implicit compliments are ambiguous and nonformulaic (cf. Boyle 2000; Herbert 1990; Jaworski 1995; Knapp et al. 1984; LewandoeskaTomaszczyk 1989). Moreover, their function as "social lubricants" which 
"grease the social wheels" (Wolfson 1983:89) is not denied but is questioned not to be the only purpose. Other interactional functions can be elicited to reach a better understanding of the speech situation. However, these functions provided above can be listed as follows:

1- Avoiding embarrassment: Utilizing one speech act for intending another is one of the strategies used by the speaker to avoid embarrassment. In example 1, $\mathrm{S}$ uses a request to pay a supposedly sincere compliment that makes the addressee unconsciously accept the compliment although he is extremely irritated.

2- Solving the verbalization problem: In certain situations the speaker does not have the appropriate lexical items to express his thought, so he/she tends to use fixed expressions to normally complete the conversation. In other words, the speaker is under considerable pressure to keep on talking during the period allotted to him; he uses implicit compliments to delay the production of a turn in which a decision is anticipated (example 2 and case 19).

3- Avoiding potential problems: If the speaker behaves explicitly to express his/her thoughts, he/she will be susceptible to certain conflicts. Utilizing implicit compliments in this way avoids the interactants' interaction problems; explicit compliments would not appropriately serve such a function (example 2 and cases 4,10 and 11). 
4- Creating a smooth atmosphere for reducing stress in certain interactions, especially arguments over the price of a certain item (example 2) or in other stressful situations (cases 9 and 15).

5- Supporting the speaker's higher self-esteem: Implicit compliments help the speaker maintain his self-image as a respected, worthy human being. It is argued that the existence of some contradictions in the speaker's statements does not affect this claim since, focusing more on our intentions and conversational goals, we, speakers, listen more attentively to what others say than to our own utterances (example 3).

6- Following the economy principle: The interlocutors need/tend to deliver two or more ideas in as few utterances as possible especially when there are limited resources; example 4 exemplifies one of these limitations, namely restricted time during telephone conversations (example 4 and cases 5 and 12).

7- Showing noble feelings: Opting for implicit compliments enables the speaker to hide his/her ignoble feelings. This is exemplified in the use of ?allahumah Sallii 9annabi, maša? allah; direct compliments are not acceptable in certain situations when the expected feeling is malicious; the case provides an example of such a feeling, envy. To clarify the claim here we can refer to Ibn Taymiyah who says: "Nobody is free from hasad, but the noble person hides it whilst the base person shows it" (the disease of the nations before you, 2013). The most 
appropriate cover is to compliment the addressee implicitly; otherwise, the speaker would be mistaken and, consequently, prone to criticism (case 1).

8- Expressing gratitude and thanks: some idiomatic phrases are frequently utilized to show that the complimenter is grateful to the addressee for something he has done (cases 3,5,6,7,8,13 and 18).

9- Substituting for other speech acts: Implicit compliments may be used instead of other speech acts; in case 14 the implicit compliment is used to indicate indirect criticism, and in case 17 it is used to express nonnegotiable, indirect acceptance.

10- Paving the way for other actions: An implicit compliment can be used as a preparatory stage for other speech acts; in case 8 the compliment serves the function of paving the way for haggling or giving a reason for a deduction if it is used by the customer himself/herself, and in case 16 it is used as a preparatory phrase for a request within the same discourse or after it.

From a sociolinguistic perspective, the researcher to some extent agrees with Boyle (2000) that implicit compliments occur in non-intimate relationships; the fact that he depends only on radio interviews to provide illustrative examples reveals that he considers the occurrence of such a speech act cannot be found in intimate relationships. The previous orientation has been reinforced by Bruti (2006); in her film data, the relation between the characters 
is a distant one. Moreover, Maíz-Arévalo (2012) states that implicit compliments are preferred when evaluating someone's qualities, achievements or personal appearance in order to avoid face-threat, especially when the relationship between the interlocutors is still distant. Although the word 'preferred' in this quotation suggests that implicit compliments may appear in intimate relationships, all the examples provided throughout her paper are related to contexts which vary from kinship relations to relations with associates, work, or clubs, and no examples of close relations are given.

However, the studies under discussion have been directed to western societies, namely, American, Italian, and Spanish respectively. Therefore, it is not necessary to expect the same tendency to occur in Jordanian Arabic. In the data collected, there are instances of implicit compliments that take place between friends and family members (cf. example 4 above). This observation will not only provide a case of differentiation between Western and Eastern communities regarding this speech act, but also explain why such a case exists; the researcher's concern here is the following question: What are the functions of using implicit instead of explicit compliments between intimate friends or family members? Reasons related to creating rapport or face-management are logically unconvincing and easily refutable since explicit compliments would perfectly serve the previous functions as implicit ones do. So there is a need for a more in-depth analysis of the compliment event in order to reach more 
convincing functions related to the compliment in its context; functions serve the complimenter, the complimentee or both.

\subsubsection{Implicit compliments as formulaic structures}

It is claimed that some cases of Jordanian Arabic implicit compliments, are formulaic in the sense that there are some words grouped together in a certain order to mean approval or appreciation. In the previous section, the researcher explains that fixed expressions are used as implicit compliments. To follow in a similar vein, the second section includes situations in which implicit compliments are found to follow fixed syntactic structures, specifically, interrogatives and exclamatory declaratives. Taking into consideration the pragmatic focus ${ }^{8}$ of each case separately, the researcher claims that implicit compliments in this section serve two functions: the first one is related to the satisfaction of curiosity (the speaker needs some information from the addressee); in such situations he expects asking for details would make the addressee feel uncomfortable since the former appears too inquisitive and curious. To avoid this problem and get the required information, the speaker opts for implicit rather than explicit compliments (examples 5-7). The second function is related to indirect persuasion; the complimenter uses an implicit

\footnotetext{
${ }^{8}$ According to Van Dijk (1998), the specific function of the global speech act of a discourse results from a network of relations between the different propositions in the same discourse. Hence, "a speech act would be under focus if it is the main act intended in a sequence of speech acts, such that the other speech acts are components or auxiliary/preparatory for that act (1998:368)." Therefore, instead of studying the speech act at the sentence level, in the following examples the researcher considers the function of the global speech act of implicit compliment at the macro-structure.
} 
compliment since it is the best way to persuade the addressee of a certain idea, and direct means of persuasion would be fruitless compared to that of implicit approval and admiration (example 8) simply because the speaker who uses direct persuasion might appear dishonest and insincere.

\section{Example 5}

[Field: Two friends are having a drink together, one of them is wearing a new, short-sleeved shirt.//Tenor: A (male, 26) and T (male, around 32) do not have a close friendship.]

1. A: šs:: (.) mištari qamiis jdii:d ?!

2. 'You have bought a new shirt?!'

3. T: aah ištariituh imbariH billayl.

4. 'Yes, I bought it yesterday night.'

5. A:layš ma qultilli, kunt ruHt ma9ak ?u jebtilli waHad zayu.

6. 'Why didn't you tell me? I would escort you and buy a similar one for me?

7. T: kunit marir min šari9 issinimah wana rayiH 9assuuq (.) šuftu u9ajabni, $\underline{\text { su }}$ rayak? Hilu?

8. 'While I was passing-by the Cinema Street in my way to the market, I accidently saw it and thought it is nice. What's your opinion? Is it nice?

9. A: aah mrattab !

10. 'Yes, it is really nice and stylish!'

Wearing a new piece of clothes is one of the most frequent cases in which compliments of both types are introduced. In this case, A reproaches $\mathrm{T}$ for buying the new shirt without accompanying him. This reproach is a strong 
indication of the compliment, especially when the complimenter told the addressee that he wants to buy a similar one for himself, and the idea is reinforced again at the end of the dialogue when he states that T's shirt is attractive. Hence, consisting of (at least) two speech acts, viz. reprimand and compliment, this speech situation can be considered as a macro-speech act, "a global speech act performed by the utterance of a whole discourse, and executed by a sequence of possibly different speech acts" (Van Dijk 1998:356). Therefore, the discourse as a whole can be considered as a macro-implicit compliment (not only the italicized phrases) in which the speech act of reprimand is a "preparatory condition" (ibid) that motivates and leads to the compliment action.

The compliment here can be read in two ways; firstly, $\mathrm{T}$ has clothes sense; he is picky and smart, so A needs to accompany him for choosing clothes. The other reading could be that the shirt is attractive and elegant. In other words, the shirt suits him well because he has a body on which anything would look good (he is neither skinny nor obese, in either way the shirt will look unattractive). In both readings, the implied meaning is positive and pleasant.

It is claimed that implicit compliments which follow the structure of interrogatives and exclamatory declaratives serve many functions, especially the one related to 'satisfying curiosity.' Curiosity is a driving force behind using 
implicit compliments in this way. The speaker's curiosity is aroused by noticing a certain item related to the addressee, so that the speaker feels a strong desire to get information about it. An implicit compliment is a suitable vehicle through which the speaker gets the information required without appearing inquisitive and rude.

Returning to our social variables, namely, social distance and age, it is noticed that they influence this situation as follows: the social distance between the interactants is large; although their relationship is developing, they are not close friends. And they belong to different age groups; A is 26 years old and T around 32. These findings consolidate the suggestion given above that the aforementioned social parameters are crucial for the constitution of implicit compliments.

\section{Example 6}

[Field: $\mathrm{M}$ and $\mathrm{G}$ work together; $\mathrm{M}$ is wearing new, elegant clothes. They have met by chance in a supermarket //Tenor: there is not any type of personal relationship except that of work between $\mathrm{G}$ (male, 40) and M (male, around 22)]

1. G: ̌̌o: M! šayfak Tali9 šo fi warak?

2. 'M, I see that you are going somewhere, what is up?'

3. M: wallahi::, wala ?iši.

4. 'By God, nothing.'

5. G: mistaYrib ya9ni HaaT 9uTur imrattab ?u libsak imrattab ?iši kөiir (0.5) 
6. mulfit linnaZar ?il marra hay $=$

7. 'Amazed, well, you have scented with fragrant perfumes, and your outfit is

8. elegant, this is extraordinary...eye-catching this time.'

9. M: ( ) wallaahi wala ?iši bas haykk.

10. 'By God, nothing, but that's it...'

11. G:Yari:::b ya9ni ? ?ilwaHad daa?iman bišuuf libsak 9aadi SaH bas libsak

12. imtaktak ?u 9ala rasak-

13. 'Strangely enough, I always see you wearing casual clothes, right? But now

14. your clothes are stylish, and on your head- .'

15. M: ?ilwaHad bizabbiT ?u::::-

16. 'One may dress up and-'

17. G: Hujtak Haki faaZy ?illaa fi ?iši ! ya9ni ha (0.4) $\underline{\text { waZiH } 9 u T r a k ~(.) ~}$

18. imtaktak

19. 'Nonsense, there must be an especial occasion, well, look, it's obvious; your

20. perfume is exciting and sexy.'

21. M: wallahi Safyih wafiah yabin il9am

22. 'By God, as usual, nothing of interest, my dear'

23. G:?ana mistaYrib ma ba9taqid ma fi ?iši != ?illa warak ?iši (.) ?imzabiT

24. ?išša9rat ?u 9amil luk jdeed ?il marra hay

25. 'I'm astonished, I didn't believe your dodge and pretense, there must be a

26. matter with you. Your hair is neatly combed with a new look this time'

27. M: la wallahi ma fi ?iši Safyiah wafiah (0.4) xaalSa wallah.

28. 'By God, as usual, nothing of interest, no matter, by God.'

29. G: 9ala raasi wallah yaa Yaali.

30. 'Warmly welcomed, my dear.'

31. M: 9ala raasi ya Yaali.

32. 'Warmly welcomed, my dear.'

33. G: Habibi 
34. 'My dear'

35. M: hala biik.

36. 'Welcome.'

As stated before, implicit compliments are found to take specific syntactic structures, namely, interrogatives and exclamatory declaratives. In this example, it appears that implicit compliments are used to hide the inquisitiveness of the speaker. In the dialogue above, the curiosity of $\mathrm{G}$ is obvious and insistent, and he needs to hide his middling in others' affairs in complimenting them. What happened in the conversation reveals how $\mathrm{G}$ takes all means possible in order to satisfy his curiosity. Being so, curiosity is a driving force behind opting for implicit rather than explicit compliments. Let's suppose that $G$ explicitly compliments the addressee on his appearance, $\mathrm{G}$ would not get any information out of $\mathrm{M}$; there would be a response (whatever it is) to the compliment, and the response in any way would end the topic. Consequently, G could not continue asking questions and ultimately could not get the needed information. So his curiosity would not be satisfied (he could not know where $\mathrm{M}$ is heading). However, the analysis given may not be convincing since $M$ avoids all the insistent inquiries and $\mathrm{G}$ does not get any information.

But the justification of the correctness of the explanation is easy to be formed and the rationale runs as follows: wearing stylish, perfumed clothes and having a new look, $\mathrm{M}$ appears to have a romantic rendezvous (at least from G's angle). Such an understanding of the situation raises many questions in G's 
head such as the following: where is $\mathrm{M}$ heading? With whom has he a relationship? Is the girl one of my neighbors? $\mathrm{M}$ was walking to his destination and the meeting place is consequently nearby. These questions cannot be directly asked; therefore, he needs an acceptable means in order to get his end. Using implicit compliments in the form of interrogatives and exclamatory declaratives, $\mathrm{G}$ avoids potential rebuke and an angry response. Consequently, $\mathrm{M}$ deems it too intimate and personal and responds to it visibly embarrassed without threatening the complimentee's face, and this is the benefit of using implicit instead of explicit compliments. Returning to the social variables of the study, social distance and age, the researcher notices that although $\mathrm{M}$ and $\mathrm{G}$ work together, the social distance between them is large since they do not frequently meet after work and at work they have few to talk about. Moreover, the interactants belong to different age groups ( $\mathrm{G}$ is 40 and $\mathrm{M}$ is around 22).

\section{Example 7}

[Field: $\mathrm{S}$ and $\mathrm{K}$ are cousins; $\mathrm{S}$ has bought a modern, expensive car. On a visit to his uncle, $\mathrm{K}$ (male, 35) finds S (male, 22) descending his car. //Tenor: although they are cousins, they meet occasionally and formally.]

1. K: kayfak ya ibin i19am?

2. 'How are you? My cousin.'

3. S: ya Hayyallah ?ahlawsahla ?ahlawsahla.

4. 'God greet you, welcome, welcome.'

5. K: šu::: lak šu: hassiyyaarah! wallahi ?innak ibtistahalha. 
6. 'Oh, what is this car?! By God, you deserve it.'

7. S: ya9ni (.) ilwaaHad ti9ib taa jaabha (.) 9ugbaalak.

8. 'By God, one cannot afford it easily, may Allah afford you with a better one in the near future.'

In the previous two cases (examples 5 and 6), it is argued that implicit compliments in the form of interrogatives and exclamatory declaratives serve a specific interactional function which is satisfying curiosity. The example under discussion supports the suggested purpose; $\mathrm{K}$ begins the conversation as usual with a phatic talk; he asks about S's health and the addressee responds as dedicated by social norms; he warmly welcomes his visitor. However, the expected turn of the speaker is not to comment on the new car, but to continue asking some relevant (and possibly irrelevant) questions about the addressee's health and his family, and in return the addressee answers the questions and asks similar ones. But what happens in the case above is a deviation of the socially accepted behaviour caused by the curiosity of the speaker; noticing the new car, $\mathrm{K}$ forgets to ask more phatic questions and satisfies himself with only one to move to an important topic which is the purchase of the new car. What counts here for $\mathrm{K}$ are questions about the car not about S's family; he earnestly wants to know when $\mathrm{S}$ bought the car, how he afforded its price and so on.

Being the situation as such, S negatively responds to K's appreciation, and the implicit compliment does not have its effect. Even S's response supports the claimed function of implicit compliments under this section; the 
response suggests that the complimentee does not feel comfortable with the complimenter's eagerness to obtain information about the car since S considers such middling in his affairs is unacceptable at all; moreover, his response ends the possibility of further investigation at least for that time of the speech event. Taking into consideration the social factors, viz, the social distance and age of the interlocutors, the researcher notices that they have considerable influence on the compliment event. $\mathrm{K}$ opts for an implicit rather than explicit compliment since the social distance between him and his cousin is significantly large and $\mathrm{K}$ being 35 and $\mathrm{S}$ being 22; they belong to different age groups.

\section{Example 8}

[Field: on a visit to his sister, B has been told by his sister that A, his nephew (male, 4), is unhappy because his outfit is not as colorful and pretty as his brother's. B's sister has told her brother that A had cried all the night and that breaks her heart. At the time of the conversation, B's sister was preparing lunch in the kitchen; B was sitting with his nephew in the parlor. //Tenor: B (male, 33) does not like $\mathrm{A}$ as much as his brother since $\mathrm{A}$ is naughty while his brother is more disciplined and cleverer.]

1. B: šu:: xaalu ta9aal ?i9Tiini bousih !

2. 'Hey, my nephew, come here, give me a kiss!'

3. A: ?a:: xaalu::::

4. 'Oh, my uncle.' ((coming near))

5. B: maa šaa?a allaah! (0.5) miin ištaralak hali bluuzeh ? maama willah 


\section{6. baaba?}

7. 'Oh God, who bought this blouse? Mum or Dad?'

8. A: maama. ištratli yaaha min ?irbid.

9. 'Mum bought it from Irbid.'

Throughout this section it is argued that implicit compliments in the form of interrogatives and exclamatory declaratives are used to satisfy the complimenter's curiosity. However, the example in hand is intentionally provided to question the applicability of the aforementioned interactional function to all implicit compliments with the same syntactic structures. In this case, the complimenter has already been given the answer to his question by his sister who told him that she had bought the shirt and the whole story about the cause of A's unhappiness; therefore, there is no inquisitiveness that needs to be fulfilled.

The situation being as such, 'satisfying nosiness' is unacceptable and 'indirect persuasion' is the possible alternative function; the rationale runs as follows: having been told that $\mathrm{A}$ is complaining about his clothes, $\mathrm{B}$ tries to soften the situation and to persuade A that his mother has a clothes sense and his clothes are stylish and elegant, using an implicit compliment in the form of interrogatives and exclamatory declarative creates the presupposition that B has not been provided with any information about the event, so the compliment would appear more sincere and genuine. And it is obvious that an explicit compliment with the same meaning would not provide the same effect, that is, 
convince the boy that his clothes are attractive and stylish. Referring to the social factors of the case under concern, the researcher notices that although they are relatives, the social distance between B and A is relatively large; moreover, they belong to different age groups since $\mathrm{B}$ is 33 and $\mathrm{A}$ is 4 .

To sum up the previous two sections, the researcher argues that treating implicit compliments as non-formulaic speech acts is questionable; in the data collected it appears obviously that implicit complimentary language can be considered in some cases formulaic from two sides: on the one hand, specific idiomatic expressions are inferred in their appropriate contexts to mean compliments, and on the other hand, some syntactic structures, specifically interrogatives and exclamatory declaratives, are utilized to imply the meaning of compliments. Moreover, it is claimed that at the discourse level, implicit compliments can be seen to have some interactional functions in addition to their social functions; functions related to satisfying curiosity and indirect persuasion are claimed to be the most noticeable motives behind the use of implicit instead of explicit compliments in the preceding section. Furthermore, the social variables of the study are relevant to a great extent in the construction and appropriateness of the speech act of implicit compliments.

\subsection{Nonformulaic implicit compliments}

In the preceding section, it is argued that implicit compliments are in some cases formulaic; such an argument leads the discussion to the other type 
of this speech act which is non-formulaic (or possibly less formulaic) implicit compliments.

\subsubsection{Implicit compliments involving comparisons}

According to Boyle (2000:35), there are two ways in which people say implicit compliments; the first involves comparing a person to someone that the speaker thinks the other person might admire. The second involves referring to something that a person has done and he or she is proud of (achievements of the addressee). Considering the first type, Boyle claims that implicit compliments related to this phenomenon are restricted in all cases to be personal, comparing a person to someone admirable; Boyle (2000:40-41) provides two illustrative examples within long pieces of discourse; for reasons of space only one of them is extracted below:

[JL (a radio interviewer) implicitly compliments his guest

KDL (a Canadian singer). He compares her voice to that of Karen Carpenter (a famous singer in 1940s).]

JL: Lovely arrangements on the album though ahm (pause) there's something that I hadn't really spotted before in you that comes out on this album there's something Karen Carpenterish about your voice on this album, is that deliberate? 
KDl: No, it's not deliberate but I have heard that comparison before ahm I I guess it would be you know the tone of voice and maybe the vibrato but (.) you know I take it as a big compliment because I am a huge Karen Carpenter fan

JL: well that's nice phew (laughs) I thought you might be worried about it

Kdl: no no

JL: I think she's a fantastic voice Karen Carpenter

Kdl: yeah (it) is yeah

The point that the researcher wants to highlight is that implicit compliments in the form of a comparison are treated by Boyle (2000) to be limited to only one type, that is to say, specific personal comparison (see MaízArévalo (2012) and Bruti (2006) for similar discussion). However, the researcher argues that implicit compliments involving comparison are found to be personal (either specific or unspecific) and impersonal as the forthcoming sections reveal.

\subsubsection{Personal comparisons}

In the literature reviewed, it appears that implicit compliments include comparisons in the sense that the speaker compares the addressee to someone that the speaker thinks the other person might admire, that is, a well-known person who has some impressive capacities or attributes. Nonetheless, in the data collected, the speech act of implicit compliments, in this case, can be 
divided into two parts: on the one hand, the comparison is specific in which the addressee is compared with a particular person; the speaker mentions the name of an admirable individual and makes a comparison between him and the complimentee if the complimentee presumes that the addressee knows the referent or without mentioning a name if the complimenter compares the addressee either to himself or to an unknown person; in such a case the complimenter presumes that the addressee does not know the referent. On the other hand, the comparison is unspecific in the sense that the speaker considers the addressee either as a member of a socially respected group, so the complimentee has as impressive qualities as the other members of the group, or as a unique person who has higher moral qualities or more impressive capacities than other people in general. In other words, specific comparison is a one-to-one relationship, while unspecific/generic comparison is a one-to-many relationship.

\subsection{Specific personal comparisons}

Implicit compliments within this category involve specific comparison in which the addressee is compared with a particular person; it is argued that the speaker, in some cases, mentions the name of an admirable individual and makes a comparison between him and the complimentee (example 9) or without mentioning a name if the complimenter compares the addressee either to himself (example 10) or to an unknown person; in such a case the complimenter presumes that the addressee does not know the referent (example 11). 


\section{Example 9}

[Field: $\mathrm{M}$ is one of the students who participated in the school broadcast; he recited some verses from the Holy Qur'an. His recitation drew K's attention since it is professional. //Tenor: K (male, 23), a newly employed teacher, does not know M (male, 11) before this incident; $\mathrm{M}$ is not one of his students.]

1. K: šwai M (.) law samaHit ta9aal ?išwai !

2. 'Hey, M, please, come here.'

3. M: ?ana (.) ?aa ?ustaað !

4. 'Me? okey, teacher.'

5. K: lamma smi9tak ?ibtiqra bil ?iðaa9a ilyuum (0.4) lafatit ?intibaahi=

6. 'When you recited the Holy Qur'an today, you drew my attention.'

7. $\mathrm{M}$ : in šaalah ma ?axTa?it.

8. 'Had I made a mistake?'

9. K: laa laa miš ?ilqaSid . bass miin darrabak ?ala ttajwiid

10. 'No no, I didn't intend that, but who taught you recitation?'

11. M: ?ana mištarik ibmarkiz qur?aani.

12. 'I have been studying at one of the Qur'anic centers.'

13. K: ibSaraaHa SuuTak? u tajwiidak maa šaa? a alaah ðakkarni ib9abdil

14. baSiT rahmatu allah 9alayh.

15. 'Honestly speaking, your hypnotic voice and your absorbing recitation

16. remind me of Abdulbasit, may Allah's mercy be upon him.'

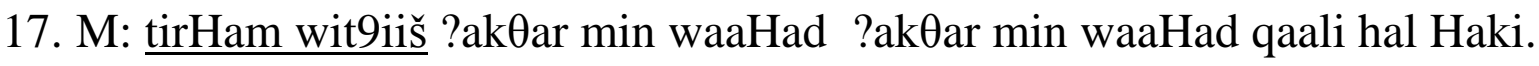
18. 'May you be blessed with long life. Many people told me the same.'

In this example, the implicit compliment (lines 13-14) is realized in terms of a comparison in which the speaker draws a parallel between the addressee and a well-known person regarding a specific trait. In such a situation, the 
discourse needs to be constructed in a way that helps the addressee make guiding inferences ${ }^{9}$ in order to correctly understand the comparison, and consequently appreciate the compliment. In the case in hand, $\mathrm{K}$ asks the sixth grader some questions regarding his recitation since he considers the boy's recitation extraordinary for one of his age. The addressee gradually makes his inferences that the speaker highly estimates his recitation; the addressee's inferences help him accept the compliment as a fact.

The researcher suggests that the existence of guiding inferences in implicit compliments involving comparison is considerably important since most, if not all, cases within this category are divided into two groups: firstly, implicit compliments that take relatively longer discourse are correctly understood and appreciated as a piece of information, a fact. Such a finding is related to the degree of clarification and elaboration of the compliment topic. Secondly, implicit compliments that take relatively shorter discourse are incorrectly interpreted as criticisms, and the speaker tries to find his way out of tight corners by expressing his intended meaning. This situation is caused by the fact that the addressee is not allotted enough time to make suitable inferences about the complimentary meaning. In support of the previous argument, Searle (1991:266) suggests that

\footnotetext{
${ }^{9}$ Lipton (2004:129) suggests that "we are constantly generating and assessing explanations." Furthermore, he states that 15 percent of all conversation concerns casual explanations. Therefore, guiding inferences are controlled and directed by diverse explanatory considerations.
} 
in indirect speech acts the speaker communicates to the hearer more than he actually says by way of relying on their mutually shared background information, both linguistic and nonlinguistic, together with the general powers of rationality and inference on the part of the hearer.

However, for the inferential strategy to be successful, according to Searle (1991:268), the addressee needs "to establish, first, that the primary illocutionary point departs from the literal, and second, what the primary illocutionary point is." Therefore, the role of inferences cannot be denied or underestimated for establishing the intended illocutionary force of the comparison.

Returning to the case under concern, $\mathrm{K}$ makes a comparison between the addressee's voice quality and recitation excellence and those of Abdulbasit Abdulsamad who is a famous Qur'anic reciter. The comparison can be understood as a compliment especially after making some hints such as K's question miin darrabak 9ala ttajwiid 'who taught you recitation?' However, the interactional function of the comparison in hand is that of encouraging the addressee to continue practicing recitation to be a famous Qur'anic reciter. Moreover, the social parameters, distance and age, affect the use of implicit compliment in this form as follows: since $\mathrm{K}$ is a novice teacher and $\mathrm{M}$ is not one of his students, the interactants do not know each other; consequently, the social 
distance between the two is large. Moreover, they belong to different age groups; $\mathrm{K}$ is 23 and $\mathrm{M}$ is 11.

\section{Example 10}

[Field: one of the telecom companies has deducted an amount of money from A, a sales person, and that angers him. A harshly complains to the call receptionist, while one of the customers, S, is shopping. //Tenor: A (male, around 33) and S (male, around 20) are neighbors, but they do not have an intimate relationship.]

1. S: bas Hakayt ma9aah bjur?a !

2. 'Oh, in courage and determination you talked to him.'

3. A: ya xi: SaaHib ilHaq qawi, šu ya9ni šu:: ?asawi ? mahum zay ilminšar

4. Taali9 maakil naazil maakil.

5. 'Within your rights, you come on strong. What should I do? They (their

6. policies) are like a saw; both forwards and backwards it cuts (they take

7. money with a right or without a right).'

8. S: nifsi ?ikuun 9indi jur? a zayyak, haðiik ?ilmarrah-

9. 'I wish to be as courageous as you, last time...

10.A: [hiyyia miš jur?a, bas ilmauZuu9 ?innu ilxaSim miš manTiqi]

11. 'It's not a matter of courage; it's just that the deduction is unjustifiable.'

In the preceding example the compliment involves comparing the addressee with a famous person, and in the case in hand the comparison involves comparing the complimentee with the speaker himself. In this case and other similar cases, the comparison contains the meaning of self-criticism on the part of the speaker, and this justifies why the complimentee does not accept the 
compliment. It appears that the speaker admires the addressee for his courage and determination since he lacks such a personal trait; he wishes to be as courageous as the addressee. However, implicit compliment in this case reveals two points: firstly, the speaker admits that he does not have enough courage to claim his rights; therefore, he is pacifist and shy. These qualities are connected with some people who underestimate their abilities and capacities, so the use of this kind of implicit compliments is considerably limited. The second point is that this kind of implicit compliments is triggered by the complimentee himself; in other words, the addressee fishes for the compliment; A plucks up his courage to speak harshly with the receptionist although he knows the call is recorded and the receptionist cannot discard the deduction. Knowing this, he possibly wants to show off in order to attract the customer's attention (the researcher observes that A was not angry before or after the call; he only pretended to appear as such).

Taking into consideration the previous two points, the researcher suggests that implicit compliments in the form of a comparison between the complimenter and the complimentee (a compliment in the form of a wish) occur in trouble-telling conversations. Being so, they provide the speaker with an appropriate means to initiate a trouble-telling topic, and the initiation of a trouble-telling topic is the interactional function of or the motivation behind the use of these compliments. Returning to the case at hand, the researcher notices 
that after implying the compliment, the complimenter tries to begin a new story about himself; the words '...haðiik ?ilmarrah-' reveal that $\mathrm{S}$ is stealing the floor to end A's story and begins a similar one in which he had an unpleasant experience, but the complimentee interrupts him and continues focusing on his own story. However, the researcher notices that social distance and age as social factors affect the speech situation since the collocutors' relationship is not intimate and they belong to different age groups; $\mathrm{A}$ is around 33 and $\mathrm{S}$ is around 20.

\section{Example 11}

[Field: Four friends are having a drink together in a cafe. At the time of the compliment, they are telling funny jokes. // Tenor: $\mathrm{H}$ (male, 28), $\mathrm{K}$ (male, 32), $\mathrm{T}$ (male, 30) have an intimate relationship except $\mathrm{M}$ (male, 27) who is recently introduced to the group by T.]

1. M: ya:: ?allaah šu ibtišbah DiHkitak DiHkit SaaHbi!

2. 'Oh God, how your laugher resembles that of my friend.'

3. H: šu:: DiHkitu Hilwih ?!

4. 'Is your friend's laughing pleasant?'

5. M: ?aa DiHkituu Hilwih ka?inha Taal?a minilqalb.

6. 'Yes, it is amazing and hearty.'

In examples 9 and 10, implicit compliments are explained to involve a comparison between the addressee and a famous person and between the addressee and the speaker, respectively. In the case in hand, the implicit 
compliment involves a comparison between the complimentee and an unknown person; the speaker refers to somebody who the addressee supposedly does not know. What is noticeable in similar cases under this category is that the compliment mostly always does not have its effect out of two reasons: firstly, the complimentee cannot identify the person with whom he has been compared, and this takes place simply because the referent is discourse-new and hearernew. Secondly, the complimenter gives the verbal gift abruptly without paving the way for it. According to Van Dijk (1998:348), topic-comment/assertionpresupposition distribution is crucial for the discourse of speech acts; known elements should come in first position and new elements in second position. Consequently, the speaker needs to begin with pragmatically presupposed element in order to be correctly understood. However, in the case in hand, the complimenter deviates the given distribution, and thus, a pragmatic failure occurs in the compliment event.

However, because of the aforementioned reasons, the addressee cannot bridge guiding inferences to help him appreciate the comparison, so he asks the speaker about his intention. In this particular case, the speaker comments on H's laugh comparing it to his friend's, intending positive implications, but he has been misunderstood and the implicit compliment does not have its positive force. Nonetheless, the implicit compliment in this particular case has a specific interactional function; the speaker utilizes this speech act in order to gain access 
to the floor and to shift the topic from telling jokes to another theme since he does not have any jokes to tell; therefore, he stays passive for a considerable time. Moreover, the social distance between the interactants is effective since M compliments a person with whom he has no relationship. Therefore, the researcher recommends that the compliment needs to be placed not only at the appropriate time in the discourse but also at the appropriate stage of the relationship. Such a consideration leads him to hypothesize that the effect of social distance between the interactants is more significant than age when interlocutors belong to the same age group.

To sum up this section, it is claimed that in specific personal comparison used as an implicit compliment the addressee is compared with a particular person; it is argued that the speaker, in some cases, mentions the name of an admirable individual and makes a comparison between him and the complimentee (example 9) or without mentioning a name if the complimenter compares the addressee either to himself (example 10) or to an unknown person; in such a case the complimenter presumes that the addressee does not know the referent (examples 11). The previous cases of comparison exemplify different interactional motives behind the use of this form of compliments; in example 9 the compliment serves the function of encouragement, in example 10 it is used as an appropriate means to initiate a trouble-telling topic, and in 
example 11 it is utilized to gain access to the floor and to shift the topic from one theme to another.

\subsection{Generic personal comparisons}

In this section, implicit compliments involve unspecific comparison in the sense that the speaker considers the addressee either as a member of a socially respected group, so the complimentee has as impressive qualities as the other members of the group (example 12), or as a unique person who has higher moral qualities or more impressive capacities than other people in general (example 13). In other words, generic compliments can be inclusive or exclusive of the addressee depending on whom he is compared and associated with.

\section{Example 12}

[Field: T goes to H's store to buy some fruit and vegetables, $\mathrm{H}$ has been recently suffering from heart disease, and most of his neighbors, including $\mathrm{T}$, know that. // Tenor: T (male, 17) and $\mathrm{H}$ (male, around 50) do not have a close relationship.]

1. T: ?išluunak 9am H. ?išluun ?axbaarak ?išluun SiHtak ?

2. 'How are you, uncle H? How are you doing? How is your health?'

3. H: ?ilHamdulillaah, ?allah ?isalmmak, ?ib ?alf xiir, ?il Hamdulillaah.

4. 'Thank God, God bless you, I'm in perfect health, praise be to Allah.'

5. T: ?išluun ?iššuyul ma9aak?

6. 'Are you satisfied with your work?' 
7. H: wallahi ?ilHamdulillaah, ?illi bit9aamal ma9 waaHad miOlak

8. ?ilHamdulillaah, ?ana ?ib ?alf ni9mih wib ?laf xayr .

9. 'By God, I'm very well, when I deal with a person like you, everything will

10. be fine, thank God.'

11. T: ?allah yis9idak $9 \mathrm{amm} \mathrm{H}$

12. 'God bless you, uncle H.'

In this case, the speaker states that when he deals with a person like the addressee, he will be in a perfect state. So the speaker draws a comparison between the addressee and a group of kind people, and in this comparison the addressee is included within such a group whose members have appreciative qualities such as benevolence and support. Although there is no direct mentioning of the other group (the second term of the comparative is omitted), the hearer is able to make his inferences; this process is known as free enrichment. Yus (2011:145) proposes that "it takes place when the utterance demands from the hearer the 'inferential filling' of some elided part. Despite being a grammatical utterance, it makes no sense unless this non-coded part is inferred correctly."

Therefore, the comparison in this case is implied to indicate two readings: the first implicature is that the addressee is benevolent and supportive because the complimenter feels fine when he deals with him. The second reading can be that other customers, H's neighbors, as well are sympathetic and warm-hearted because $\mathrm{H}$ states that he deals with individuals like the addressee, so he is not 
dealing only with the hearer, but also with other people having the same qualities. However, this analysis supports the claim that explicit and implicit compliments are mutually exclusive; an implicit compliment cannot be replaced with an explicit compliment in the same dialogue since although they may have nearly the same meaning, each one has its implicatures and interactional functions.

Returning to the example in hand, the researcher points that the implicit compliment in the form of obscure comparison is used to achieve two conversational goals: firstly, it serves as an expression of gratitude in which the complimenter thanks the addressee for his concerns. The other goal may be argued as follows: the speaker is tired as it appears in his mode and wants the hearer to stop asking private questions. The situation being as such, the speaker needs to interrupt the addressee and to gently stop him (topic shift). The best means to achieve this end is to compliment the hearer implicitly; the subsequent dialogue, as observed by the researcher, supports this understanding. However, the social factors of the study are influential as follows: the social distance between $\mathrm{T}$ and $\mathrm{M}$ is large, and they belong to different age groups ( $\mathrm{T}$ is 17 and $\mathrm{H}$ is around 50).

\section{Example 13}

[Field: after shopping, $\mathrm{K}$ wants to go to the mosque to attend al-jum'a sermon, he has a heavy bag and does not know where to put it. He decides to put it in the 
supermarket near his house. // Tenor: K (male, 28) and A (male, around 30) do not have an intimate relationship.]

1. K: marHaba jaar. kayf SiHtak ?

2. 'Hello, my neighbor, how are you?'

3. A: ?allah yis9idak, ?ilHamdullillaah.

4. 'God bless you, fine.'

5. K: bidi ?ayalbak, jaar, biddi ?axalli ?ilkiis 9indak, bidi ?atwaZah wa Salli

6. 'Can I ask you a favor, my dear? I want to leave this bag in your store for I

7. am in a hurry to attend the sermon.'

8. A: wala ihimmak, ya zalama, ?ilmaHal ?u SaHaabu 9ala Hsaabak

9. 'Do not worry, man. Think of the store as yours, and me as your brother

10. (you are welcome).'

11. K: manta ibti9raf, ma ba?ammin bil Haara 9ala Hada ?illa ?inta

12. 'You know, I cannot trust anyone but you in this area.'

13. A: lah ya zalamih, bas maalu ibraahiim ?

14. 'Oh man! What about Ibrahim?'

15. K: ibraahi:::m ?! salaam salaam !

16. 'Ibrahim?! Goodbye goodbye (no comment).'

In example 9, the implicit compliment involves a comparison between the addressee and noble people, so its implicature carries positive meanings for the complimentee and for other individuals with whom the addressee is associated. In this case, the situation is different; the implicit compliment also involves a comparison between the addressee and other people, but here the comparison carries positive connotations only for the addressee and negative ones for other people. The speaker suggests that the complimentee is the only trustworthy 
neighbor in the surrounding area (lines 10-11); other neighbors are not as honest as the addressee. This implicature is reinforced and confirmed in the subsequent dialogue when the addressee pretends to deny the comparison in this way to ask about the opposite store owner, the addressee emphasizes the compliment by exclaiming that Ibrahim is unreliable as well (possibly, the most unreliable person).

Moreover, the complimentee asks about a specific person in order to specify the comparison, and, consequently, the compliment would be more meaningful and more effective. However, the interactional function of the compliment may be considered as an expression of thanking, but this function is not the only one; the other and probably the most salient goal is preparing the addressee to willingly accept similar requests in the future (the speaker cannot trust other neighbors, so he has a right or at least a reason to ask similar favors from the addressee, and it will become one of the addressee's moral obligations to accept). Furthermore, the analysis of the case in hand becomes clearer considering the social distance between the interlocutors, A and $\mathrm{K}$ do not have an intimate relationship.

To conclude, implicit compliments in this section involve unspecific comparison in the sense that the speaker considers the addressee either as a member of a socially respected group, so the complimentee has as impressive qualities as the other members of the group (example 12), or as a unique person 
who has higher moral qualities or more impressive capacities than other people in general (example 13). In addition to their function as an expression of thanks and gratitude, in the former example, the implicit compliment serves the function of shifting the topic, and in the latter example it is utilized as a preparatory stage for future demands and requests.

\subsubsection{Impersonal comparisons}

In the previous section, implicit compliments involve personal comparisons in the sense that the speaker compares the addressee to an admirable person (specific comparison one-to-one relationship) or to a group of people (unspecific comparison one-to-many relationship). However, the cases under this section exemplify another way of comparison in which the speaker uses metaphor to implicitly compliment the addressee. In addition to its aesthetic, rhetorical and other uses, metaphor can be used assertively; Bergmann (1991:486) suggests that

The fact that metaphors "generate" further and further readings does not, however, conflict with the claim that an author can successfully use a metaphor to convey a fairly specific cognitive content. For a person who uses a metaphor to make an assertion typically does not intend to assert everything that we can "read into" the metaphor. Nor the audience typically attribute all of those readings to the author. 
In the case of assertive metaphor, Bergmann (1991:487) distinguishes between sentence meaning and speaker meaning since "a particular sort of relation must hold between the sentence used and the proposition asserted." She (1991:488) states that a sentence like 'John is an Einstein' carries the proposition 'John is a brilliant scientist.' The proposition asserted is "a function of the literal meaning of 'John' and the salient characteristics associated with 'Einstein'." Further, she suggests that although the context determines which salient characteristics to be associated with an entity, "there are still the culturally shared beliefs the stereotypes that stay with us" (ibid). Nevertheless, for the success of an assertive metaphor, she (1991:489) proposes three conditions as follows:

(i) The audience must recognize the author's utterance as a metaphor; the utterance cannot be taken literally.

(ii) The audience must recognize the author's utterance as an assertion.

(iii) The audience, depending on the conversational setting and culturally shared beliefs, must identify the proposition the author intends to assert.

Returning to the discussion of implicit compliments, the researcher notices that some assertive metaphors are used to implicate compliments; the complimenter opts for a metaphorical use of language to intend or convey a positive proposition _ approval and appreciation. In the following examples, the speaker compares the addressee to an inhuman entity such as an animal 
(example 14) or an object (example15) with the illocution force of a compliment. However, in these examples and other similar ones, it is observed that the comparison is specific in the sense that it is a one-to-one relationship.

\section{Example 14}

[Field: the family went to Al-Himma for picnic and swim, the next day one of their relatives visited them and asked about their vacation. The following extract centered on M (male, 8) who is the youngest brother. // Tenor: F (male, 17) meets his cousin $\mathrm{R}$ (male, 9) frequently but their relation can be characterized as that of reciprocal rivalry and sometimes enmity.]

1. F: šu: šu::: ?imbariH kuntu tisbaHu ?! kaayf, ma9quul M bi9raf yisbaH

2. 'What a story! Yesterday you were swimming, how about M? I think he

3. could not swim!'

4. R: sa:ma:kah !

5. 'A fish'

6. ((M remains silent and anticipatory $))$

This example is slightly different from the previous ones; the complimentee is an overhearer of the dialogue, and the compliment is not directed to him in the usual way described before. $\mathrm{F}$ in his question about $\mathrm{Z}$ tries to make him the laughing stock of the whole family; therefore, Z's positive face is threatened since the participants of the dialogue may laugh at him, so he is in a tight situation. To save him, his brother $\mathrm{R}$ implicitly and indirectly compliments him in a holistic way; comparing the complimentee's swimming 
ability to that of a fish is more successful than answering F's question and then defending the complimentee; the latter choice would lead to more arguments and more face-threatening situations. Moreover, the implicit compliment that involves impersonal comparison is more functional in this case than that of personal comparison.

Furthermore, the implicit compliment under concern has a very salient purpose; it saves the complimentee's positive face, and using an explicit compliment in this dialogue would not yield the same effect or serve the aforementioned purpose. Taking into consideration the social distance between interactants and their age, the researcher notices that they extremely influence the compliment event since the interlocutors' relationship is not intimate and they belong to different age groups ( $\mathrm{F}$ is 17 and his cousin $\mathrm{R}$ is 9 ).

\section{Example 15}

[Field: $\mathrm{H}$ meets his uncle $\mathrm{S}$ who has recently returned from America. In this visit they talked about many political and social issues. Throughout the conversation, $\mathrm{H}$ could not gain access to the floor except occasionally; his uncle $\mathrm{S}$, being knowledgeable, talkative and charismatic, has been talking all the time, and that considerably impressed $\mathrm{H}$ who has not seen his uncle for two years. // Tenor: $\mathrm{H}$ (male, 27) and $\mathrm{S}$ (male, 48) are relatives, but they do not have a close relationship.] 
1. H: wallaahi la yummal, ibti9raf, Hakiina bmawaZii9 k0iir.

2. 'What a funny time we've spent! (It's nice/ interesting talking to you) Well, we talked about many issues.'

3. S: mauZu::9 bijur mauZu:9, ( ), wilHayaa ( ) -

4. 'One topic leads to another, ... and the life...'

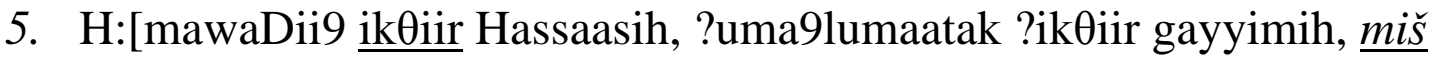

6. ibwijhak! wiSSalaatu 9annabi, mausuu9a]

7. 'Many crucial issues (we've talked about), your information is

8. enlightening. Honestly speaking, (you are) an encyclopedia.'

9. S: kullu min luTfak ?u zuuqak, ?u (.) bas lu nixlaS min hannas ?illi ?illi

10. bni9tabirhum ibniqdar ni9tabirhum SaTHiyyiin, ?u:: ma binZuru ?illa lil

11. gušuur.

12. 'Thank you a lot, you are so kind. Oh, if only other people could think as

13. deeply as you do!'

In the previous example the compliment includes a comparison between the addressee and an animal (fish). In this case, the implicit compliment involves a comparison between the addressee and an object; in order to express his admiration and appreciation for his uncle, the speaker implicitly compliments his uncle by comparing him to an encyclopedia. This comparison has a positive connotation such as that the addressee is very knowledgeable about everything; in each and every field, he has useful information. In addition to accepting the compliment and thanking his nephew for his cordiality, the complimentee implicitly compliments the speaker; he refers to other people who are illogical and insensible. In this reference, the speaker excludes his nephew from this category and the exclusion is an implicit compliment in the sense that 
the complimentee thinks deeply of serious issues. Claiming such a trait to characterize the complimentee, the speaker accepts the first compliment (being as informative as an encyclopedia) as a fact and thanking the complimenter sincerely for it.

The first compliment serves the function of leave-taking; the speaker implicitly complimenting the addressee before his leaving suggests he was interested in his uncle's speech, and his leaving is related to any cause except that of boredom. The second compliment has the interactional function of expressing thanks and making a ground for the first compliment by giving it a reason, in other words, reinforcing the compliment; the first compliment is admitted to be a fact because the complimenter thinks deeply, and his way of thinking makes him admit that the addressee is knowledgeable. Taking into consideration the variables of the study, it appears that they affect the case in hand since the social distance between the interactants is large and they belong to different age groups. ${ }^{10}$

To sum up, some assertive metaphors can be used to implicate compliments; the complimenter opts for a metaphorical use of language to intend or convey a positive proposition _ approval and appreciation. In the cases above, the addressee is compared to an inhuman entity such as an animal (example 14) or an object (example15) with the illocution force of a

\footnotetext{
${ }^{10}$ Other similar comparisons observed include comparing an English teacher to a dictionary, a Math teacher to a computer, a Geography teacher to an atlas and a hard worker to a machine.
} 
compliment. However, in the aforementioned examples the compliment serves three functions respectively: saving the complimentee's positive face, leavetaking and reinforcing a compliment.

\subsubsection{Implicit compliments referring to achievements}

According to Boyle (2000:35), there are two ways in which people say implicit compliments; the first involves comparing a person to someone that the speaker thinks the other person might admire (the previous section). The second involves referring to something that a person has done and he or she is proud of (achievements of the addressee). Considering the second type, Boyle (2000:36) provides the following example:

"You've worked with Elizabeth Taylor!"

And Bruti (2006:193) provides another example (Film: Sabrina):

D: Well, I may know nothing of Dow Jones, but I do know something about kisses.

L: You could lecture on that at Vassar.

However, implicit compliments referring to achievements are relatively rare compared with the previous categories; the researcher notices that only three instances of this type are among the data collected. In addition to their rarity, implicit compliments referring to achievements have the shadow of 
comparison; the achievements of the addressee are estimated according to the achievements of others. The researcher does not include the following examples within the previous category simply because the addressee is not compared with anyone or with anything (personal or impersonal comparison); the focus of the compliment is related to the achievements of the complimentee instead of the complimentee himself. The examples below are illustrative:

\section{Example 16}

[Field: An English teacher is giving a lesson about present simple, students are tired and bored after having five classes before.//Tenor: the relationship between $\mathrm{H}$ (male, around 27) and $\mathrm{C}$ (male, 13) is intimate since $\mathrm{H}$ (the teacher) is friendly and supportive and likes his students. A (male, 13) is another student in the same class.]

1. C: ostaað gaday::š ?issa9ah ?

2. 'What time is it, teacher?'

3. H: batwagga9iš HiSSti halqad mugrifih !

4. 'I do not expect my class to be that boring!'

5. C: miš qaSdi, ostaað.

6. 'I did not mean that, teacher.'

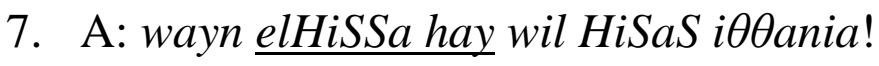

8. 'Compared with other classes, this class is really funny and more

9. interesting.'

10. H: Sadaqtak kөiir wallah. ((teasingly))

11. 'I extremely believe you.' 
(A and other students laugh.)

As can be clearly seen in this example, $\mathrm{H}$ gets from the level of expressed meaning (asking for the time) to the level of implied meaning (the class is tiresome and boring). $\mathrm{H}$ presupposes that learning grammar, especially at that time (the sixth class), is uninteresting. In order to express that he is sensitive and caring, he teases the students by directing the blame to his class. In doing so, H's desire to be liked and approved of is apparent; consequently, his positive face is threatened if there is no compliment given afterwards. Fortunately, A's compliment restores the teacher's positive face. At the same time, the researcher also notices that A's compliment results as an obligation for saying something nice at that moment when the teacher goes fishing for compliments. The situation being as such, it is safe to say that the implicit compliment referring to H's achievements (his class is considerably interesting) serves a specific function which is restoring the addressee's positive face. Moreover, in order to save his teacher, A chooses an implicit compliment to be accepted as a genuine one and the teacher's response reveals that the compliment has been appropriately interpreted. However, taking into consideration the social factors of this case, namely, distance and age, the researcher notices that only the age variable affects the situation since the social distance between $\mathrm{H}$ and his students is small, to some extent the relationship between them is friendly and intimate. 


\section{Example 17}

[Field: While an English teacher in the classroom was giving a lesson, a student's father came asking about the progress of his son.//Tenor: $\mathrm{H}$ (male, 28) teaches $\mathrm{T}$ (male, around 44) 's son. $\mathrm{T}$ meets $\mathrm{H}$ for the first time.]

1. D: wallahi kөiir irtiHit ?ana ya ostaað (.) lamma: Hakaali $F$ inno raH

2. itdarishum kaman inqli:zi issanih hay.

3. 'By God, I was very pleased when F (my son) told me that you will teach

4. him (as well as his classmates) English this year.'

5. H: wallahi 9afikra ?ana ixtarthum la?inno $F$ bas biinathum wallah (.) ?allah

6. yis9idak.

7. 'By God, I choose to teach this class only because $\mathrm{F}$ is one of them.'

This case is more interesting than the previous one; two implicit compliments referring to achievements are articulated. The first one is that of $\mathrm{T}$ which can be read as follows: 'you are really a good teacher, you have mostly all the characteristics of a successful teacher: qualification, dedication, patience and the like.' $\mathrm{D}$ chooses to state indirectly his admiration for the teacher in order to appear honest and serious so the compliment would be accepted. Moreover, in order to justify the compliment, D specifies that the source of his admiration is his son. In Van Dijk's words (1998:357), "the more reliable a given source, the higher the credibility of the assertion based on it." However, T's reply reveals that the compliment is correctly interpreted; he returns the compliment with another compliment which has the following implicature: 'you 
are a great father; you are tolerant, devoted, open-minded and the like.' However, the two compliments are appreciated and welcomed by the interactants and this is one of the advantages of implicit compliments.

However, the first implicit compliment serves the function of expressing gratitude; instead of directly stating that he is truly grateful to the teacher that he had passed his son, D implicitly compliments the teacher. Therefore, the compliment may be understood to implicate the following: Your support and aid to my son is something I'll never forget. Your thoughtfulness is greatly appreciated. I am very happy that you will teach him another year because I hopefully expect the same treatment. The second implicit compliment supports this understanding since the speaker affirms that the addressee's son is a brilliant student (although he is not). This implicit affirmation suggests that the speaker downgrades what he has done in order to show modesty and selfeffacing; so it is safe to say that the second compliment serves the function of expressing modesty and avoiding self-praise. Taking into consideration the social variables effective in this case, the researcher notices that the social distance between the interactants is small since they do not meet before this incident, and they belong to different age groups; $\mathrm{H}$ is 28 and $\mathrm{T}$ is 44 .

To conclude, implicit compliments referring to achievements are said to serve different functions; the cases above exemplify this claim by pointing to three motives behind the use of implicit compliments, viz, restoring the 
addressee's positive face, expressing gratitude and expressing modesty and avoiding self-praise. Nonetheless, this chapter is hoped to provide convincing answers to the research questions concerning the topics of implicit compliments in Jordanian Arabic, the interactional functions speakers try to achieve, the effects of social distance and age on the production of and the response to implicit compliments, the effect of the context on the implicit compliment behavior, and the possibility of replacing an implicit compliment by an explicit one. Moreover, the discussion confirms the hypotheses given in the previous chapter regarding the systematicity of the speech act under concern; the researcher notices that it follows specific paths and patterns. Secondly, implicit compliments can be considered in some cases formulaic and in others nonformulaic; they do not have apparent semantic and syntactic patterns. Thirdly, they are correlated with some extra-linguistic variables (i.e., topic, participants and setting) as well as social variables. Finally, the motivations of using implicit compliments are completely different from those of explicit compliments. However, the researcher provides in details the answers of the research questions and the main findings of the study in the following chapter. 


\section{Chapter Five}

\section{Summary, Conclusions and Recommendations}

This chapter aims to provide a comprehensive, brief summary of the study and a detailed discussion of the major findings of the research in relation to the questions of the study outlined in chapter three. In addition, it provides some useful recommendations and suggestions for further research.

\subsection{Summary}

This thesis is a sociopragmatic study of the speech act of implicit complimenting among Jordanian people in which the researcher follows the ethnomethodological approach in order to "discover the interpretive practices through which interactants produce, recognize, and interpret their own and others' actions" (Pomerantz 1988:361). Such an approach renders the speech act of implicit compliment as an undivided, integral part of the discourse in which it occurs. Adopting this orientation enables the researcher to focus on the motives behind choosing implicit compliment instead of an explicit one at a specific time of the discourse. In the first chapter it is explained that compliments have three articulations, explicit, implicit and indirect or embedded realizations, and Holmes' (1988:446) definition is considered to be the most appropriate one for it provides the linguistic and social features of the term in hand. Moreover, it is shown how implicit compliments are considered to be indirect speech acts since their illocutionary force is realized by the context 
rather than the literal meaning of certain words used in the utterance. Regarding the notion of 'face,' it is explained that implicit compliments cannot be considered as a positive or negative politeness strategy without referring to the context in which the speech act occurs. In other words, complimenting as a speech act is culture-bound and context-bound. The situation being as such, the researcher highlights the importance of contextuality in complimenting in order to reach a better understanding of the compliment behaviour as an inseparable part of a discourse. Moreover, the functions of compliments are reviewed and explained to be concentrated on the social ones with a complete neglect of interactional functions. Based on the community's ideology and the speech situation, the main topics for compliments are appearance, clothing, emotions, helping and service, performance, personality traits and possessions. Considering the responses of compliments, the researcher agrees with Herbert's (1990:208-211) orientation towards the different varieties of the responses since the recipients of compliments face two conflicting constraints: to accept the compliment and at the same time to avoid self-praise. And this interactional dilemma leads to a variety of responses ranging from the acceptance of the compliment to the rejection of it.

In chapter two, the review of the literature reveals that explicit compliments are extensively studied; according to Golato (2002, cited in Golato, 2003), explicit compliments have been studied in detail in eleven 
different languages and in six varieties of English alone, and they have been studied from a variety of different perspectives as well. In sharp contrast with the extensive literature on explicit compliments, implicit compliments are rarely studied; to the best knowledge of the researcher, there are only three articles on the topic, namely Boyle's (2000), Bruti’s (2006) and Maíz-Arévalo’s (2012) articles. The studies under discussion have been directed to western societies, namely, American, Italian, and Spanish respectively, and they deal with the topic from one perspective, viz. from a pragmatic point of view. However, the fact that implicit compliments are rarely considered is caused by three reasons: (i) the methodology commonly employed and (ii) the restricted view of the phatic function of compliments (Boyles 2000) and (iii) the rare occurrence of this speech act in conversations (Maíz-Arévalo 2012). Unlike the previous researchers' orientation which restricts the study to the notion of face threatening and enhancing, and consequently, leads to a narrow view of the speech act under concern, the researcher's orientation is based on the argument that a better understanding of implicit compliments can be attained when this speech act is studied from a different angle unrelated to the theory of face. And this would lead to different results and findings as the following section reveals. 


\subsubsection{Findings}

\subsubsection{Cases of implicit compliments}

In contrast with previous studies which emphasize the nonformulaicity of implicit compliments (cf. Boyle's (2000), Bruti's (2006) and Maíz-Arévalo's (2012) articles), this thesis finds that implicit compliments may occur formulaically in two ways: firstly, idiomatic expressions, some word clustering yields fixed or semi-fixed phrases used as implicit compliments, and secondly, idiomatic syntactic structures, implicit compliments in the form of interrogatives and exclamatory declaratives. Such a view questions and denies the nonformulaicity of this speech act at least for the speech community under examination.

Considering the nonformulaic implicit compliments, the researcher agrees with Boyle (2000:35) that there are two ways in which people say implicit compliments; the first involves comparing a person to someone that the speaker thinks the other person might admire. The second involves referring to something that a person has done and he or she is proud of (achievements of the addressee). Considering the first way, Boyle (ibid) claims that implicit compliments related to this phenomenon are restricted in all cases to be personal, comparing a person to someone admirable. However, unlike other researchers' findings (see Maíz-Arévalo (2012) and Bruti (2006) for similar orientation as that of Boyle (2000)) that the comparison is restricted to be 
personal and specific, the researcher argues that implicit compliments involving comparison can be personal or impersonal. On the one hand, personal comparisons are found to be specific and unspecific. They are specific in the sense that the addressee is compared with a particular person; the speaker mentions the name of an admirable individual and makes a comparison between him and the complimentee if the complimentee presumes that the addressee knows the referent or without mentioning a name if the complimenter compares the addressee either to himself or to unknown person, in such a case the complimenter presumes that the addressee does not know the referent. Moreover, the comparison can be unspecific in the sense that the speaker considers the addressee either as a member of a socially respected group, so the complimentee has as impressive qualities as the other members of the group, or as a unique person who has higher moral qualities or more impressive capacities than other people in general. In other words, specific comparison is a one-to-one relationship, while unspecific/generic comparison is a one-to-many relationship.

On the other hand, implicit compliments involving comparison can also be impersonal in which the speaker compares the addressee to a nonhuman entity such as an animal or an object with the illocution force of a compliment. Utilizing assertive metaphors, the complimenter opts for a metaphorical use of language to intend or convey a positive proposition, approval and appreciation. However, in the examples discussed and other cases observed, it is noticed that 
impersonal comparisons are specific in the sense that they involve a one-to-one relationship. Nonetheless, the second way in which Jordanians use nonformulaic implicit compliments includes a reference to achievements of the addressee; the speaker refers to something that the addressee has done and he or she is proud of. It is pointed that implicit compliments referring to achievements are relatively rare compared with the previous categories; the researcher notices that only three instances of this type are among the data collected. In addition to their rarity, implicit compliments referring to achievements have the shade of comparison; the achievements of the addressee are estimated according to the achievements of others. However, this section provides a brief review of the main findings regarding the cases in which compliments are conducted implicitly; what remains to be included are some concluding remarks concerning answers of the research questions, and this will be the aim of the next section.

\subsubsection{Revisiting the research questions}

Throughout the thesis the researcher tries to find suitable, acceptable answers concerning the research questions which are provided to confirm the hypotheses mentioned in chapter three. The research questions are hoped to guide and pave the way for the researcher to find the differences between explicit compliments and implicit ones, on the one hand, and between Jordanian speech community and other speech communities (see chapter two for a review 
of other findings regarding other western cultures), on the other hand. However, the research questions deal with the most significant issues related to the speech act of implicit compliment, and their answers would hopefully provide the reader with the full picture of the topic under discussion. For convenience and clarity, the research questions are relisted below:

1. What are the topics of implicit compliments in Jordanian Arabic?

2. What are the response types to implicit compliments in Jordanian Arabic?

3. What are the speaker's motivations/needs to opt for an implicit instead of an explicit compliment (i.e. the interactional functions speakers try to achieve)?

4. What are the effects of some social factors, viz. social distance and age, on the production of and the response to implicit compliments?

5. How is implicit compliment behavior affected by the context in Jordanian Arabic?

6. Can an implicit compliment be replaced by an explicit one in the same speech situation? If not, why?

In what follows findings related to each question are provided respectively in subheadings.

\section{Topics of implicit compliments}


In a previous section (1.6. Topics of compliments), it is stated that in complimenting, the speaker attributes a specific positive quality he/she likes most about the addressee. Being the situation as such, the speech act of complimenting involves many different topics such as appearance, clothing, emotions, helping and service, performance, personality traits and possessions. The preference of a certain topic over another is determined not only by interactants but also by the society as a whole. Therefore, what is appropriate to compliment on in a specific context and/or culture is an important factor to be taken into consideration for both types of compliments. However, the previous notions are applicable for both types of compliments, viz. explicit and implicit compliments, but what is special about implicit compliments is the fact that complimenters using them focus more on personality traits than on other topics as the following distribution of topics shows:

(i) Personality traits: Compliments regarding the addressee's personality and character can be found in examples 2- 4, 9-13, 15, 16 and in other cases related to idiomatic expressions 4,6,8,9,14,15,16,17,18.

(ii) Clothing: Complimenting on the complimentee's clothes can be found in examples 1, 5, 6 and 8 .

(iii) Helping and service: This topic is only found in idiomatic phrases related to cases 3, 5, 7 and 13 . 
(iv) Appearance: Like the previous topic, it is found only in idiomatic phrases (see cases 2, 10 and 11).

(v) possessions: Speakers tend to use formulaic phrases to comment on and appreciate the addressee's possessions (see case 1 and example 7)

(vi) Emotions: Complimenting on emotions is considerably rare; it is encountered only in case 12 .

(vii) Performance: Similar to the preceding tendency, speakers rarely use implicit compliments for appreciating the addressee's performance (e.g., case 14), and it is noticed that speakers prefer explicit compliments for the last two topics or no compliment at all.

\section{Responses to implicit compliments}

Regarding responses to explicit compliments, it is explained in a previous section (1.7. Compliment responses) that, according to Pomerantz (1978:81-82 cited in Chen 2010: 80), the recipients of compliments face two conflicting constraints:
A) Agree with and/or accept compliments
B) Avoid self-praise

Because of the interactional dilemma addressees face, many different responses are found to surface in compliment events. The situation being as such, Herbert (1990), for example, discusses twelve compliment response types found in 
American English. These types are relisted below in order to explain the differences between responses to explicit compliments and those to implicit compliments:

Response types

Agreement

$$
\begin{aligned}
& \text { Acceptance 1. Appreciation token } \\
& \text { "Thanks" } \\
& \text { 2. Comment acceptance } \\
& \text { "Yeah, it's my favorite too." } \\
& \text { 3. Praise upgrade } \\
& \text { "Really brings out the blue in } \\
& \text { my eyes, doesn't it?" }
\end{aligned}
$$

Nonacceptance

4. Comment history

"I bought it for the trip to

Arizona"

5. Reassignment

"My brother gave it to me"

6. Return

"So's yours"

$\underline{\text { Nonagreement }}$

7. Scale down

"It's really quite old"

8. Question

"Do you really think so?"

9. Disagreement

"I hate it."

10. Qualification

"It's alright, but Len's is nicer"

11. No acknowledgement

[silence]

Other

Interpretations

\section{Request interpretation}

"You wanna borrow this one too?"

(Herbert 1990:208-211)

Taking into consideration that there are many different responses to explicit compliments (twelve response types), the researcher finds that only one 
response type to implicit compliments pervades in each and every case explained in this thesis as well as in other unmentioned cases. In other words, it is found that complimentees accept the compliment in one way or another, and this finding parallels that of other researchers (cf. Boyle, 2000; Maíz-Arévalo ,2012; and Bruti ,2006). This finding suggests that the interactional dilemma described above is not of any importance concerning implicit compliments simply because we do not have a dilemma at all; instead of facing two constraints, complimentees find only one constraint, that is to say, the first one. And the other constraint is not effective because the compliment does not include any direct assessment or appreciation; hence, there is no direct selfpraise. In short, addressees unconsciously accept the compliment. However, any misunderstanding between the interactants does not need to be considered as a response because the compliment in such situations does not take its required time; some implicit compliments need to be taken as a global speech act at the macro level (see footnote 8). Nonetheless, acceptance of implicit compliments can be realized in two different ways, explicitly or implicitly as illustrated below:

1- Thanking the speaker explicitly for his cordiality: the complimentees use some conventional words and phrases in the meaning of 'thank you a lot' (see examples 1-4 and 12).

2- Thanking the speaker implicitly for his compliment either as 
(a) a confirmation of the compliment : the addressee elaborates the topic a little bit further, focusing on himself and the object of the compliment by downgrading the compliment to achieve a specific aim or remaining silent to indicate an indirect agreement and acceptance (see examples 5- 11, 13, 14 and 16).

Or as (b) an inclusion of the speaker: the complimentee shows his appreciation and acceptance of the compliment by paying the speaker an implicit compliment as a response (see examples 15 and 17)

Therefore, there is only one response type of implicit compliments, and that suggests that implicit compliments in most, if not all, cases are less threatening speech acts for both of the interactants. The situation being as such, the researcher argues that their use is really more profitable than that of explicit ones since addressees take them as a matter of fact or a piece of information rather than as a flattery comment. However, these advantages are not the only ones that speakers and addressees gain from opting for implicit rather than explicit compliments; other benefits can be crystal clear if interactional functions are taken into concern and account.

\section{Motivations or functions of implicit compliments}

It is argued in this thesis that there are external (social) and internal (interactional) functions of implicit compliments. Firstly, internal functions are 
related to the compliment event itself and are derived and determined at the time of the dialogue while external functions are related to the speech act in isolated utterances; thus, they are derived from the speakers' general knowledge about the illocutionary force of the compliments. The second difference between external and internal functions is that the former concentrates on the illocutionary force; what the speaker wants to do with the compliment, that is to say, the effect of creating and maintaining friendly relationships and that of attending positive and negative face wants (enhancing politeness and saving face). The internal functions focus on the illocutionary and perlocutionary effects behind the use of the speech act under concern; effects on both of the interactants (and possibly on the overhearers as well). Such functions cannot be attained unless the interpreter (whether a participant in the dialogue or not) can sensitively analyze the discourse in order to reach particular impressions resulted and created by the context. Nonetheless, implicit compliments can be used to achieve many different internal (interactional) functions which can be distributed as follows:

a- Functions serving the speaker: in certain situations, the researcher notices that the main function of using an implicit compliment at a specific time of the dialogue serves only the complimenter, such a claim is in sharp contrast to the general assumption provided in the literature on compliments which focuses on the fact that utilizing compliments serves only the addressee (i,e., to make the 
addressee feel good about himself). However, such a narrow view is not satisfactory and it is not confirmed in the discussion of implicit compliments. Nonetheless, the following functions are argued to be related more to the complimenter than to the complimentee:

1- Avoiding embarrassment: The speaker uses a request to pay a compliment that makes the addressee unconsciously accept the compliment. In example 1, the complimenter uses the speech act of requesting to indicate a compliment, and in doing so, he avoids potential embarrassment.

2- Solving the verbalization problem: The speaker does not have the appropriate lexical items to express his thought, so he/she tends to use fixed expressions to complete the conversation normally. In other words, the speaker is under considerable pressure to keep on talking during the period allotted to him; he uses implicit compliments to delay the production of a turn in which a decision is anticipated (see example 2 and case 19).

3- Supporting the speaker's higher self-esteem: Implicit compliments help the speaker maintain his self-image as a respected, worthy human being. It is argued that the existence of some contradictions in the speaker's statements does not affect this claim since, focusing more on our intentions and conversational goals, we, speakers, listen more attentively to what others say than to our own utterances (see example 3). 
4- Following the economy principle: The speaker needs/tends to deliver two or more ideas in as few utterances as possible especially when there are limited resources; example 4 exemplifies one of these limitations, namely restricted time during telephone conversations (see also cases 5 and 12).

5- Showing noble feelings: Opting for implicit compliments enables the speaker to hide his/her malicious feelings. This is exemplified in the use of ?allahumah Sallii 9annabi, maša? allah; direct compliments are not acceptable in certain situations when the expected feeling is malicious; case 1 provides an example of such a feeling, envy. To clarify the claim here we can refer to Ibn Taymiyah who says: "Nobody is free from hasad, but the noble person hides it whilst the base person shows it" (the disease of the nations before you, 2013). The most appropriate cover is to compliment the addressee implicitly; otherwise, the speaker would be mistaken and, consequently, prone to criticism (see case 1 and the utilization of the same phrase in example 9).

6- Expressing gratitude and thanks: Implicit compliments are frequently utilized to show that the complimenter is grateful to the addressee for something he has done (see cases 3,5,6,7,8,13 and 18 and examples 12,13, and 17).

7- Substituting for other speech acts: The speaker uses implicit compliments instead of other speech acts; in case 14 the implicit compliment is used to indicate indirect criticism, and in case 17 it is used to express nonnegotiable, indirect acceptance. 
8- Paving the way for other actions: An implicit compliment can be used as a preparatory stage for other speech acts; in case 8 the compliment serves the function of paving the way for haggling or giving a reason for a deduction if it is used by the customer himself/herself, and in case 16 it is used as a preparatory phrase for a request within the same discourse or after it.

9- Satisfying curiosity: Complimenters use implicit compliments as a suitable vehicle through which they get the information required without appearing inquisitive and rude (see examples 5-7).

10- Indirectly persuading the addressee: The complimenter uses an implicit compliment since it is the best way to persuade the addressee of a certain idea, and a direct means of persuasion would be fruitless compared to that of implicit approval and admiration (see example 8).

11- Initiating a trouble-telling topic: The speaker uses implicit compliments as a transitory stage for introducing an unpleasant topic; such a topic may be deemed as unwelcomed theme to turn the conversation into. In example 10, the speaker utilizes an implicit compliment as an appropriate means to initiate a troubletelling topic.

12- Gaining access to the floor and shifting the topic from one theme to another: In example 11, it is explained how the speaker uses an implicit compliment in order to gain access to the floor and to shift the topic from telling jokes to 
another theme since he does not have any jokes to tell and that makes him stay passive for a considerable time. So, utilizing an implicit compliment at that time of the conversation serves the complimenter a lot.

13- Preparing the addressee for certain demands: Implicit compliments are used as a preparatory stage for future demands and requests; in example 13, it is explained how the complimenter uses an implicit compliment to imply that he cannot trust other neighbors, so he has a right or at least a reason to ask similar favors from the addressee, and it will become one of the addressee's moral obligations to accept future demands and requests from the speaker.

14- preparing the addressee for departure: The speaker uses an implicit compliment as a sign or a hint for leave-taking; in example 15, implicitly complimenting the addressee before his leaving, the speaker indicates that he is interested in his uncle's speech, and his leaving is related to any cause except that of boredom. So, in such a case the speech act of implicit compliment serves the speaker by providing him with a means to soften the departure since it is more polite to use an implicit compliment to end the conversation and prepare the addressee for the speaker's leave-taking.

15- Expressing modesty and avoiding self-praise: The speaker uses an implicit compliment to solve the interactional dilemma described by Pomerantz (1978:81-82) in which the recipient of the compliment faces two conflicting 
constraints, that is to say, to accept the compliment and at the same time to avoid self-praise (see example 17).

b- Functions serving the addressee: Implicit compliments do not only serve the speaker but also serve the addressee as well. In some situations, the speech act of complimenting is oriented toward a specific goal related to the complimentee as the following functions suggest:

1- Saving the complimentee's positive face: The speaker provides an implicit compliment in order to save the addressee from being mocked at. Such a use is exemplified in example 14.

2- Restoring the addressee's positive face: Although highly related to the previous one, this function is completely different; in cases where the speaker uses an implicit compliment to restore the addressee's positive face, the addressee, being a participant of the dialogue, goes fishing for compliments and, consequently, threatens his positive face (see example 16). In the former case, the addressee does not put himself in the difficult situation in which his face is threatened and he is not a participant of the conversation (see example 14).

3- Encouraging the addressee: The speaker utilizes an implicit compliment in order to strengthen the effect of an utterance in which he wants to encourage the addressee to continue doing something positive (see example 9). 
4- Making a ground for a previously paid compliment: Using an implicit compliment as a continuation of a response to a given compliment, the speaker upgrades the compliment by commenting and reinforcing it. Doing so, he makes the ground for the first compliment and makes himself worthy of receiving it (see example 15).

c- Functions serving both of the speaker and the addressee: Being aimed to serve the speaker or the addressee separately, implicit compliments are found in situations where they are utilized to serve both of the interactants as the following functions indicate.

1- Avoiding potential problems: If the speaker behaves explicitly to express his thoughts, the conversation may turn into a conflict; therefore, utilizing implicit compliments in this way avoids the interactants interaction problems (see example 2 and cases 4, 10 and 11).

2- Creating a smooth atmosphere: Compared with the previous function, this one occurs in more conventional situations in which the speaker pays the compliment to reduce an already existing stress (i.e., reducing stress in certain interactions especially arguments over the price of a certain item (example 2) or in other stressful situations (cases 9 and 15)).

To sum up, it is crystal clear that implicit compliments have the aforementioned functions which are related to the speaker, the addressee or 
both, respectively. This view increases the value of this speech act since it can be used to fulfill many interactional, cognitive and social aims. Amazingly enough, implicit compliments, although directed to the addressee, are found to have more functions related to the speaker, and this finding suggests that speakers using implicit compliments are self-oriented people; the constitution and timing of this speech act are found to benefit the complimenter in the first place. Consequently, the researcher hypothesizes that an implicit compliment is a self-oriented speech act, while an explicit compliment, on the other hand, is an other-oriented speech act ${ }^{11}$. Nevertheless, it is safe to say that an implicit compliment is a function-indicating device that serves many interactional functions.

\section{Effects of social distance and age on implicit compliments}

In the preceding sections, three research questions are hopefully answered and considered. However, the fourth question is concerned with the effects of some social variables on the production of and the response to implicit compliments. For reasons described in a previous section (3.5. Variables of the

\footnotetext{
${ }^{11}$ Such a claim needs to be confirmed by other studies on the speech act in hand. Unfortunately, previous researchers have studied and treated compliments according to their general world knowledge of the benefits and reasons of using this speech act, in addition to their treatment of implicit and explicit compliments as being two sides of the same coin. The researcher argues that in order to see clearly the differences between implicit and explicit compliments, researchers need to consider them as two different speech acts. To reach this end, researchers need to study implicit compliments from within, i.e., at the discourse level. So, findings will be different to what lay people think and assume.
} 
study), the researcher deals with only two variables, viz. social distance and age. In every example above, it is highlighted how social distance and age have an undeniable influence in situations where the speech act in hand is used, and it is clarified that implicit compliments are utilized more when the social distance between the interactants is high and they belong to different age groups. In short, not in all cases the social factors of the study have their assumed effects; in some situations one of them has not any weight at all as the following distribution shows:

* the social distance is not effective in examples 4 and 16

* the age variable is not effective in examples 2 and 11

Being a qualitative study, this thesis does not provide any percentages to indicate the extent to which the aforementioned variables are effective. And the need to conduct a quantitative study is still necessary to complete and confirm the findings here ${ }^{12}$ if the demerits of quantitative data collection procedures are avoided in a certain way.

Nevertheless, the previous findings suggest that the social variables affect the use of implicit compliments without explaining the reason behind such a tendency; what remains to be provided is the answer to the following question:

\footnotetext{
${ }^{12}$ The researcher mentions the reasons behind opting for a qualitative instead of a quantitative study in a previous section (see 3.6. Data collection).
} 
Why does an implicit compliment occur between strangers and interactants of different age groups? Van Dijk (1998:382) suggests that

at the socio-cognitive basis of pragmatics, groups, group relations, and group membership are involved in the general (abstract) and specific (concrete, contextual)appropriateness of acts and interaction. This means that such a sociocognitive account must itself be based on a broader theory of social and cultural structures and relations, both at the micro level of everyday interaction, as well as at the macro level of societal organization.

Therefore, the social variables, depending on what is appropriate at the sociocognitive basis of our interaction, affect the production of and the response to implicit compliments in the way described above; in other words, it is more appropriate in Jordanian Arabic to opt for an implicit rather than an explicit compliment in situations where speakers of different age groups have a distant relation since the collective conscious and unconscious mind of Jordanians organize, direct and affect the appropriate way for interaction.

\section{Implicit compliment behavior and the effect of the context}

The importance of taking the context into consideration has given a separate section in the first chapter in which the researcher finds that compliments in general cannot be taken for granted as a positive politeness strategy without considering the discourse in which they occur. This fact is confirmed by many researchers (cf. Mills, 2003:219; Holmes, 1995:119; Eckert and McConnell-Ginet, 2003:146) who suggest that the functions of 
compliments are determined by two processes, viz. the encoding process on the part of the speaker and the decoding process on the part of the addressee; these two processes can be suitably understood and correctly analysed only if the analyst (a participant in the dialogue or an overhearer) is concerned with the speech event as a holistic undividable unit.

In other words, analysts need to analyze compliments from two different perspectives, the intended meaning of the speaker and the interpreted meaning of the addressee. This view appears crystal clear in both explicit and implicit compliments, but for implicit compliments, it is more indicative since the positive meaning of the compliment is not inherent in the words themselves; complimentees depend on their inferences in order to understand the intended meaning of the utterance (what is implicated by speakers in conversations).

To a great extent, the previous notions are relevant and applicable to the speech community under concern, namely Jordanian Arabic. In this community, the researcher notices that a better understanding of implicit compliments cannot be attained without following the domain of discourse analysis in which context is considered, according to Van Dijk (2001:356),to consist of such categories such as the overall definition of the situation, setting (time and place), ongoing actions (the field includes the preceding three categories), participants in various communicative, social or institutional roles, as well as their mental representations: goals, knowledge, opinions, attitudes, and 
ideologies (the tenor includes the previous two categories). However, the researcher, focusing on all the aforementioned categories, pays a special care to and concentration on the last category since the interpretation of a particular utterance to be related to the speech act of implicit complimenting cannot be reached without taking into consideration the mental representations of the interactants; the researcher, being an overhearer of the situations discussed (the examples mentioned in Ch.4), can determine the interactants' goals, attitudes, opinions and the like more than the reader of the same examples who may suggest different analyses and interpretations simply because the researcher alone has the advantage of being present at the time of a certain dialogue, and that provides him with a better understanding (and confines him to limited interpretations). In short, the speech act of implicit complimenting cannot be studied in isolated sentences; it needs to be examined in a larger discourse whose components (the categories mentioned above) determine its constitution and interpretation. Providing such an argument, the discussion of the given examples, to some extent, can be justified on a practical ground since the researcher and the researcher alone can decide how and why the discussion provided is designed in the way given not in other ways.

\section{The interchangeability between explicit and implicit compliments}

The fifth and last research question is concerned with the possibility of replacing the speech act of implicit compliment with that of explicit 
compliment. The answer of this question is frequently referred to throughout the thesis; in many examples the researcher draws the reader's attention to the fact that an implicit compliment in a particular situation cannot be replaced by an explicit one simply because the whole discourse will yield different results concerning not only the production of the compliment as explicitly or implicitly delivered but also the responses, attitudes, comprehension and other related issues. And this leads the researcher to suggest that explicit and implicit compliments are not simply two different realizations or articulations of the same speech act, but rather they are two different speech acts. Each one has its own constitution, organization and interpretation, and replacing one for the other in the same utterance will inappropriately yield dramatic consequences on the discourse as a whole. The situation being as such, the researcher, claiming and arguing that explicit and implicit compliments are two different speech acts, paves the way for looking at the previous subheadings and their findings from a different angle; that is to say, we need to look at implicit compliments as a distinct speech act that has its own features and implications, and applying our general assumptions about it as being simply a compliment will be disadvantageous to the extent that the whole study will be a speculative one that cannot in any way touch upon the truth.

\subsection{Conclusions}

Based on the previous findings, the researcher concludes the following: 
1- The speech act of implicit compliments is completely different from explicit ones not only in their construction and organization but also in their illocutionary force. This leads the researcher to claim that implicit and explicit compliments are not two sides of the same coin, but rather they are two different speech acts.

2- Applying discourse analysis to the study provides the researcher with more specific functions related to the context in which the speech act occurs. Throughout the thesis, interactional functions are claimed to be more representative and more illustrative of the speech event than the social functions.

3- Reviewing the cases in which implicit compliments occur confirms that implicit compliments are similar to other speech acts regarding the systematicity of their organizations and constructions.

4- Implicit compliments are concluded to be very complex speech act that conveys many functions and are affected by many factors. And this is caused by the implicitness of this speech act.

\subsection{Recommendations}

This section discusses limitations of the study and directions for further research. The researcher proposes three ways in which the current study can be extended in the future. 
1) This research uses a qualitative approach in examining Jordanian implicit compliments. The researcher suggests that implicit compliments to be studied quantitatively.

2) The study focuses only on the effect of two social variables, namely, age and social distance on Jordanian implicit compliments. Other variables such as gender, ethnicity, religion, status, etc., are recommended for they may have significant effects on production of implicit compliments.

3) The thesis is concerned only with dialogic, oral and spontaneous discourse. Other types of discourse, such as pre-planned oral discourse (e.g., interviews on television or radio), monologic (e.g., diaries) or dialogic written discourse (e.g., ceremonious compliments at birthdays and other special occasions) are not included. Therefore, other studies dealing with other norms are recommended.

4) This study focused on implicit compliments in Jordanian culture. It is recommended that other studies to be conducted on other Arabic cultures. 


\section{References}

Adachi, C. (2007). A Pragmatic Study of Gender-Based Compliments and Compliment Responses amongst Young Adults in Japan and Britain. Unpublished M.A Thesis. Kumamoto: Kumamoto University, Japan. <http://artsfaculty.auckland.ac.nz/staff/?UPI=mmey023>

Adachi, C. (2011). A Sociolinguistic Investigation of Compliments and Compliment Responses among Young Japanese. Unpublished Doctoral Dissertation. Edinburgh: The University of Edinburgh.

Araki, S. \& Barnlund, D. (1985). Intercultural Encounters: The Management of Compliments by Japanese and Americans. Journal of Cross- Cultural Psychology,16(1),9-26.

$<$ http://www.carla.umn.edu/cgibin/carla/anchor.pl?/speechacts/bibliogra phy/compliments.html::barnlund85>

Atkinson, J. \& Heritage, J. (1984). Structures of Social Action: Studies in Conversation Analysis. Cambridge: Cambridge University Press.

Austin, J. (1962). How to Do Things with Words. Cambridge, Mass: Harvard University Press.

Baxter, L. (1984). An Investigation of Compliance-gaining as Politeness. Human Communication Research, 10(3), 427-456. 
Bergmann, M. (1991). Metaphorical Assertions. In: S. Davis (Ed.), Pragmatics: A Reader (pp.485-494). Oxford: Oxford University Press.

Billmyer, K. (1990). 'I really like your lifestyle': ESL Learners Learning How to Compliment. Penn Working Papers in Educational Linguistics, 6 (2), $31-48$.

<http://www.eric.ed.gov/ERICWebPortal/search/detailmini.jsp?_nfpb=tr ue\&_\&ERICExtSearch_SearchValue_0=ED335937\&ERICExtSearch_S earchType_0=no\&accno=ED335937>

Boyle, R. (2000). 'You've worked with Elizabeth Taylor!': Phatic Functions and Implicit Compliments. Applied Linguistics, 21(1), 26-46.

Brown, P. \& Levinson, S. (1987). Politeness: Some Universals in Language Usage. Cambridge: Cambridge University Press.

Brown, R. \& Gilman, A. (1960). Pronouns of Power and Solidarity. In: T. A. Sebeok (Ed.), Style in Language (pp. 253-276). Cambridge: MIT Press.

Bruti, S. (2006). The Translation of Implicit Compliments in Subtitles. The Journal of Specialized Translation, 6 (1),185-197. <http://www.jostrans.org/issue06/art_bruti.pdf> 
Chafe, W. (2001). The Analysis of Discourse Flow, In D. Schiffrin, D. Tannen and H. E. Hamilton (Eds.) The Handbook of Discourse Analysis (pp.673-687). Oxford: Blackwell.

Chen, R. (2010). Compliment and Compliment Response Research: A Cross-cultural Research. In Anna Trosborg (Ed.) Pragmatics across Languages and Cultures (pp.79-105), Denmark: Walter de Gruyter.

Chung-hye, H. (1992). A Comparative study of Compliment Responses: Korean Females in Korean Interactions and in English Interactions. Working Papers in Educational Linguistics, 8 (2), 17-31.

<http://www.eric.ed.gov/ERICWebPortal/search/detailmini.jsp?_nfpb=tr ue\&_\&ERICExtSearch_SearchValue_0=ED354726\&ERICExtSearch_S earchType_0=no\&accno=ED354726>

Creese, A. (1991). Speech Act Variation in British and American English. Penn Working Papers in Educational Linguistics, 7 (2), 37-58.

<http://www.gse.upenn.edu/wpel/sites/gse.upenn.edu.wpel/files/archives /v7/v7n2Creese1.pdf>

Daikuhara, M. (1986). A Study of Compliments from a Cross-cultural Perspective: Japanese vs. American English. Working Papers in Educational Linguistics, 2(2), 103-134. 
<http://www.carla.umn.edu/cgibin/carla/anchor.pl?/speechacts/bibliogra phy/compliments.html::daikuhara86>

Eckert, P. (1997). Age as a Sociolinguistic Variable. In: F. Coulmas (Ed.), Handbook of Sociolinguistics (pp. 151- 67). Oxford: Basil Blackwell.

Eckert, P. \& McConnel-Ginet, S. (2003). Language and gender. Cambridge: CambridgeUniversityPress. $<$ http://www.4shared.com/office/NpXPUNR5/Language_and_Gender__P_Eckert.html>

Garfinkel, H. (1967). Studies in Ethnomethodology. Englewood Cliffs, NJ: Prentice-Hall. <http://books.google.jo/books/about/Studies_in_Ethnomethodology.htm 1?id=zj_leg8-tIEC\&redir_esc=y>

Golato, A. (2002). German Compliment Responses. Journal of Pragmatics,2 (34),547-571. <http://www.sciencedirect.com/science/article/pii/S037821660100040>

Golato, A. (2003). Studying Compliment Responses: A Comparison of DCTs and Recordings of Naturally Occurring Talk. Applied Linguistics, 24(1), $90-121$.

< http://applij.oxfordjournals.org/content/24/1/90.short> 
Grice, P. (1969). Utterer's Meaning and Intentions. The Philosophical Review,1(68), 147-77.

<http://www.jstor.org/discover/10.2307/2184179?uid=3738320\&uid=21 29\&uid=2\&uid=70\&uid=4\&sid=21101357802791>

Grice, P. (1975). Logic and Conversation. In P. Cole and J. L. Morgan (Eds.), Syntax and Semantics 3: Speech Acts (pp. 41-58). New York: Academic Press.

Gumperz, J. (1982). Discourse Strategies. Cambridge: Cambridge University Press.

<http://www.scribd.com/doc/44610674/Gumperz-Discourse-Strategies>

Gumperz, J. (1992).Contextualization and Understanding. In A. Duranti and C. Goodwin (Eds.) Rethinking Context: Language as an Interactive Phenomenon(pp. 229-252). Cambridge: Cambridge University Press.

Gumperz, J. (1999). On Interactional Sociolinguistic Method. In S. Sarangi and C. Roberts (Eds.) Talk, Work, and Institutional Order (pp.453-472). Berlin: MoutondeGruyter.

$<\mathrm{http} / / /$ books.google.jo/books/about/Talk_Work_and_Institutional_Orde r.html?id=gQt0QgAACAAJ\&redir_esc=y> 
Halliday, M. \& Hassan, R. (1976). Cohesion in English. Malaysia: Pearson Education Ltd.

Herbert, R.(1986). Say "thank you" - or something. American Speech, 61(1), 76-88.

$<\mathrm{http} / /$ www.jstor.org/discover/10.2307/454710?uid=3738320\&uid=212 9\&uid=2\&uid=70\&uid=4\&sid=21101357802791 >

Herbert, R. (1990). Sex-based Differences in Compliment Behavior. Language inSociety, 19,201-224.

<http://www.jstor.org/discover/10.2307/4168132?uid=3738320\&uid=21

29\&uid=2\&uid=70\&uid=4\&sid=21101357802791>

Herbert, R. (1997). The Sociology of Compliment Work in Polish and English.

In: N. Coupland and A. Jaworski (Eds.), Sociolinguistics(pp. 487-500).

London: Macmillan.

$<\mathrm{http} / / / \mathrm{www}$.deepdyve.com/lp/de-gruyter/the-sociology-of-complimentwork-an-ethnocontrastive-study-of-polish-qsB6kSp2GR>

Hernández-Herrero, A.(1999). Analysis and Comparison of Complementing Behavior in Costa Rican Spanish and American English. Kañina, 23 (1), 121-31.

<http://www.carla.umn.edu/speechacts/sp_pragmatics/Compliments/co mpli_resources.html> 
Holmes, J. (1986). Compliments and Compliment Responses in New Zealand English. Anthropological Linguistics, 28(4), 485-508.

$<\mathrm{http} / / / \mathrm{www}$.jstor.org/discover/10.2307/30028355?uid=3738320\&uid=2 129\&uid=2\&uid=70\&uid=4\&sid=21101357802791>

Holmes, J. (1988) Paying Compliments: A Sex Preferential Politeness Strategy. Journal of Pragmatics, 12, 445-465.

< http://www.sciencedirect.com/science/article/pii/0378216688900057>

Holmes, J. (1995). Women, Men and Politeness. London: Longman. <http://www.questia.com/library/3149271/women-men-and-politeness>

Holmes, J. (1990). Apologies in New Zealand English. Language in Society, 19, 155-199.

Holmes, J. \& Brown, D. (1987). Teachers and Students Learning about Compliments.TESOLQuarterly,21(3),523-546. <http://www.jstor.org/discover/10.2307/3586501?uid=3738320\&uid=21 29\&uid=2134\&uid $=2 \&$ uid $=70 \&$ uid $=4 \&$ sid $=21101357802791>$

Jaworski, A. (1995). 'This is not an Empty Compliment!' Polish Compliments and the Expression of Solidarity. International Journal of Applied Linguistics, 5(1),63-94. 
<http://onlinelibrary.wiley.com/doi/10.1111/j.1473-

4192.1995.tb00073.x/abstract>

Johnson, D. (1979). Entertaining and Etiquette for Today. Washington, DC: Acropolis.

$<\underline{\text { http://www.amazon.com/Dorothea-Johnsons-entertaining-etiquette- }}$ $\underline{\text { today/dp/0874912415> }}$

Kelley, H. H., Berscheid, E., Christensen, A., Harvey, J. H., \& Huston, T. (1983). Analyzing Close Relationships. In H. Kelley, E. Berscheid, A. Christensen, J. Harvey, T. Huston, G. Levinger, E. McClintock, L. Peplau, and D. Peterson (Eds.), Close Relationships (pp. 20-67). New York: Freeman.

Knapp, M., Hopper, R. \& Bell, R. (1984). Compliments: A Descriptive Taxonomy. Journal of Communication, 34(4), 12-31. <http://onlinelibrary.wiley.com/doi/10.1111/j.14602466.1984.tb02185.x /abstract>

Kryston-Morales, C. (1997). The Production of Compliments and Responses in English by Native Spanish Speakers in Puerto Rico: An Intercultural Pragmatics Study. New York: New York University. 
$<$ http://www.carla.umn.edu/speechacts/sp_pragmatics/Compliments/co mpli_resources.html>

Lakoff, R. (2003). Nine Ways of Looking at Apologies: The Necessity for Interdisciplinary Theory and Method in Discourse Analysis, In D. Schiffrin, D. Tannen and H. E. Hamilton (Eds.), The Handbook of Discourse Analysis (pp.199-214). Oxford: Blackwell. <http://onlinelibrary.wiley.com/doi/10.1002/9780470753460.ch11/summ ary>

Laver, J. (1981). Linguistic Routines and Politeness in Greeting and Parting. In F. Coulmas (Ed.): Conversational Routine: Explorations in Standardized Situations and Prepatterned Speech. The Hague: Mouton. <http://www.citeulike.org/user/schulman/article/7678206>

Leiter,K . (1980). A Primer on Ethnomethodology. Oxford: Oxford University Press. <http://books.google.jo/books/about/A_primer_on_ethnomethodology.h tml?id=H7rpAAAAIAAJ\&redir_esc=y >

Lorenzo-Dus, N. (2001). Compliment Responses among British and Spanish University Students: A Contrastive Study. Journal of Pragmatics, 33(1), $107-27$.

< http://www.sciencedirect.com/science/article/pii/S0378216699001277> 
Maíz-Arévalo, C. (2012). 'Was that a compliment?’ Implicit Compliments in English and Spanish. Journal of Pragmatics, 44 (1), 980-996.

Manes, J. (1983). Compliments: A Mirror of Cultural Values. In: Wolfson, N., and Judd, E., (Eds.), Sociolinguistics and Language Acquisition (pp. 96-102) Rowley:NewburyHouse.

$<$ http://www.gse.upenn.edu/wpel/sites/gse.upenn.edu.wpel/files/archives /v2/v2n2Daikuhara>

Manes, J. \& Wolfson, N. (1981). The Compliment Formula. In: F. Coulmas(Ed.), Conversational Routine (pp. 115-132). Mouton: The Hague.

$<$ http://www.amazon.com/Conversational-Routine-ExplorationsStandardized-Communication/dp/9027930988 >

Matsuura, H. (2004). Compliment-giving Behavior in American English and Japanese. JALT Journal, 26(2), 147-170.

Meyerhoff, M. (1999). Sorry in the Pacific: Defining Communities, Defining Practices. Language in Society, 28(2), 225-238. <http://www.jstor.org/discover/10.2307/4168926?uid=3738320\&uid=21 29\&uid=2134\&uid=2\&uid=70\&uid=4\&sid=21101357802791> 
Mills, S. (2003). Gender and Politeness. Cambridge: Cambridge University Press.

<http://www.cambridge.org/gb/knowledge/isbn/item1114321/?site_local e=en_GB>

Nakajima, Y. (1996). Politeness Strategies in the Workplace: Which Experiences Help Japanese Businessmen Acquire American English Native-like Strategies? Working Papers in Educational Linguistics, 13(1), 49-69.

< http://www.carla.umn.edu/speechacts/bibliography/refusals.html >

Nelson, G., Bakary, W., \& Batal, M. (1996). Egyptian and American Compliments: Focus on Second Language Learners. In S. M. Gass and J. Neu (Eds.), Speech Acts across Cultures: Challenges to Communication in a Second Language (pp. 109-128). Berlin: Mouton de Gruyter. <http://applij.oxfordjournals.org/content/17/4/411.short>

Papi, M. (2009). Implicitness, In J. Verschueren and J.Östman (Eds.), Key Notions for Pragmatics (PP.139-162). Philadelphia: John Benjamins Publishing Company.

Placencia, M. \& Yépez, L. (1999). Compliments in Ecuadorian Spanish.Revista Lengua, 9 (1), 83-121. 
< http://www.carla.umn.edu/speechacts/bibliography/compliments.html>

Pomerantz, A. (1978). Compliment Responses: Notes on the Cooperation of Multiple Constraints, In J. Schenkein (Ed.), Studies in the Organisation of Conversational Interaction (pp. 79-112). New York: Academic Press. <http://www.academia.edu/808256/Compliment_responses_Notes_on_th e_co-operation_of_multiple_constraints>

Qanbar, N. (2012). Compliments in the Yemeni Society: A Sociolinguistic Perspective. Journal of Language Studies, 12(3), 999-1017.

Searle, J. (1969). Speech Acts. Cambridge: Cambridge University Press.

<http://books.google.jo/books/about/Speech_Acts.html?id=t3_WhfknvF0 C\&redir_esc $=\mathrm{y}>$

Searle, J. (1991). Indirect Speech Acts. In: S. Davis (Ed.), Pragmatics: A Reader (pp.265-277). Oxford: Oxford University Press.

Slugoski, B. \& Turnbull, W. (1988). Cruel to be Kind and Kind to be Cruel: Sarcasm, Banter, and Social Relations. Journal of Language and Social Psychology, 7(2), 101-121.

Spencer-Oatey, H. (1996). Reconstructing Power and Distance. Journal of Pragmatics, 26 (1), 1-24. 
Stubbs, M. (2001). Computer-assisted Text and Corpus Analysis, In D. Schiffrin, D. Tannen and H. E. Hamilton (Eds.) The Handbook of Discourse Analysis (pp.304-320). Oxford: Blackwell.

Tang, C. \& Zhang, G. (2009). A Contrastive Study of Compliment Responses among Australian English and Mandarin Chinese Speakers. Journal of Pragmatics, 41(2), 325-345.

< http://www.sciencedirect.com/science/article/pii/S0378216608001331>

The Disease of the Nations before You. (2013, January 2). Retrieved from siratemustaqeem:

<http://www.siratemustaqeem.com/phpBB/viewtopic.php?f=28\&t=2904 \&start $=0>$

Van Dijk, T. (2001). Critical Discourse Analysis, In D. Schiffrin, D. Tannen and H. Hamilton (Eds.) The Handbook of Discourse Analysis (pp.352371). Oxford: Blackwell.

Van Dijk, T. (1998). The Pragmatics of Discourse, In A. Kasher (Ed.) Pragmatics Critical Concepts (pp.345-384), London: Routledge.

Wieland, M. (1995). Complimenting Behaviour in French/American Crosscultural Dinner Conversations. The French Review, 68(5), 796812. 
$<$ http://www.jstor.org/discover/10.2307/397851?uid=3738320\&uid=2129 \&uid=2134\&uid=2\&uid=70\&uid=4\&sid=21101357802791>

Wierzbicka, A. (1987). English Speech Act Verbs: A Semantic Dictionary. New York: Academic press. <http://www.amazon.com/English-Speech-ActVerbs-Dictionary/dp/0123128110>

Wierzbicka, A. (1991). Cross-Cultural Pragmatics. The Semantics of Human Interaction. Berlin \& New York: Mouton de Gruyter.

Wolfson, N. (1981). Invitations, Compliments and the Competence of the Native Speaker. International Journal of Psycholinguistics, 24(4), 7-22.

< http://psycnet.apa.org/psycinfo/1984-22628-001>

Wolfson, N. (1983). An Empirically Based Analysis of Complimenting in American English, In N. Wolfson and E. Judd (Eds.), Sociolinguistics and Language Acquisition (pp. 82-95). Rowley Mass: Newbury House.

Wolfson, N. (1984). Pretty is as Pretty Does. A Speech Act View of Sex Roles. Applied Linguistics, 5(3), 236-244.

<http://applij.oxfordjournals.org/content/5/3/236.extract>

Ylänne-McEwen, V. (1993). Complimenting Behaviour: A cross-cultural Investigation. Journal of Multilingual and Multicultural Development, 14(1), 499- 508. 
<http://www.tandfonline.com/doi/abs/10.1080/01434632.1993.9994551

\#preview>

Yu, M. (2003). On the Universality of Face: Evidence from Chinese Compliment Response Behavior. Journal of Pragmatics, 35, 16791710.

<http://www.sciencedirect.com/science/article/pii/S0378216603000742

$>$

Yuan, Y. (2001). An Inquiry into Empirical Pragmatics Data-Gathering Methods: Written DCTs, Oral DCTs, Field Notes, and Natural conversations. Journal of Pragmatics, 33(1), 271-292.

Yus, F. (2011). Cyberpragmatics: Inter-Mediated Communication in Context. Amsterdam: John Benjamins.

Zuo, H. (1988). Verbal Interactions of Compliment in American English and Chinese, In Hu Wenzhong (Ed.), Intercultural Communication: What It Means to Chinese Learners of English (pp. 117-136). Shanghai: Shanghai Translation Publishing House.

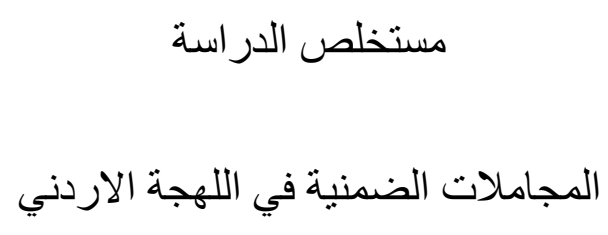




\section{اعداد: حسين حميد حسين البطاينة \\ اشر اف: الاستاذ الدكتور محمود وردات}

تهاف هذه الاطروحة الى دراسة المجاملات الضمنية في المجتمع الاردني من منظور براجماتي اجتماعي. عمد الباحث الى اتباع منهج الاثثومثيدولوجي للاكتثاف تركيب هذه المجاملات وتنظيمها، باعتبار انها جزء لا يتجزأ من الخطاب الذي تحدث فيه، اعتماد هذا التوجه مكن الباحث من التركيز على الدوافع وراء استخدام هذه الدجاملات بدلا من اخرى صريحة. وتبين نتائج الدراسة ان المجاملات الضمنية تخدم العديد من الوظائف و المهام التفاعلية للمتحدث و المتلقي وكليهما معا على حد سواء. وان ردود المتلقين لهذا النوع من المجاملات تختلف كليا عن تللك التي تعود على المجاملات الصريحة، ولذلك قد خلصت الدراسة الى اهمية در اسة هذا النوع من المجاملات بمعزل عن الدجاملات الصريحة حيث ان هذه المجاملات تنتمي الى مجمو عة منفصلة من الملفوظات، وحتى يتم ذلك لابد من در استها بمعزل عن نظرية الادب ( Politeness Theory).

الكلمات الدالة: الضمنية، الصراحة، الملفوظات، تحليل الخطاب، الاستدلالات، البراغماتية، اللغويات الاجتماعية 